Document downloaded from:

http://hdl.handle.net/10251/57050

This paper must be cited as:

Robles Martínez, A.; Ruano García, MV.; Ribes Bertomeu, J.; Ferrer, J. (2013). Advanced control system for optimal filtration in submerged anaerobic MBRs (SAnMBRs). Journal of Membrane Science. 430:330-341. doi:10.1016/j.memsci.2012.11.078.

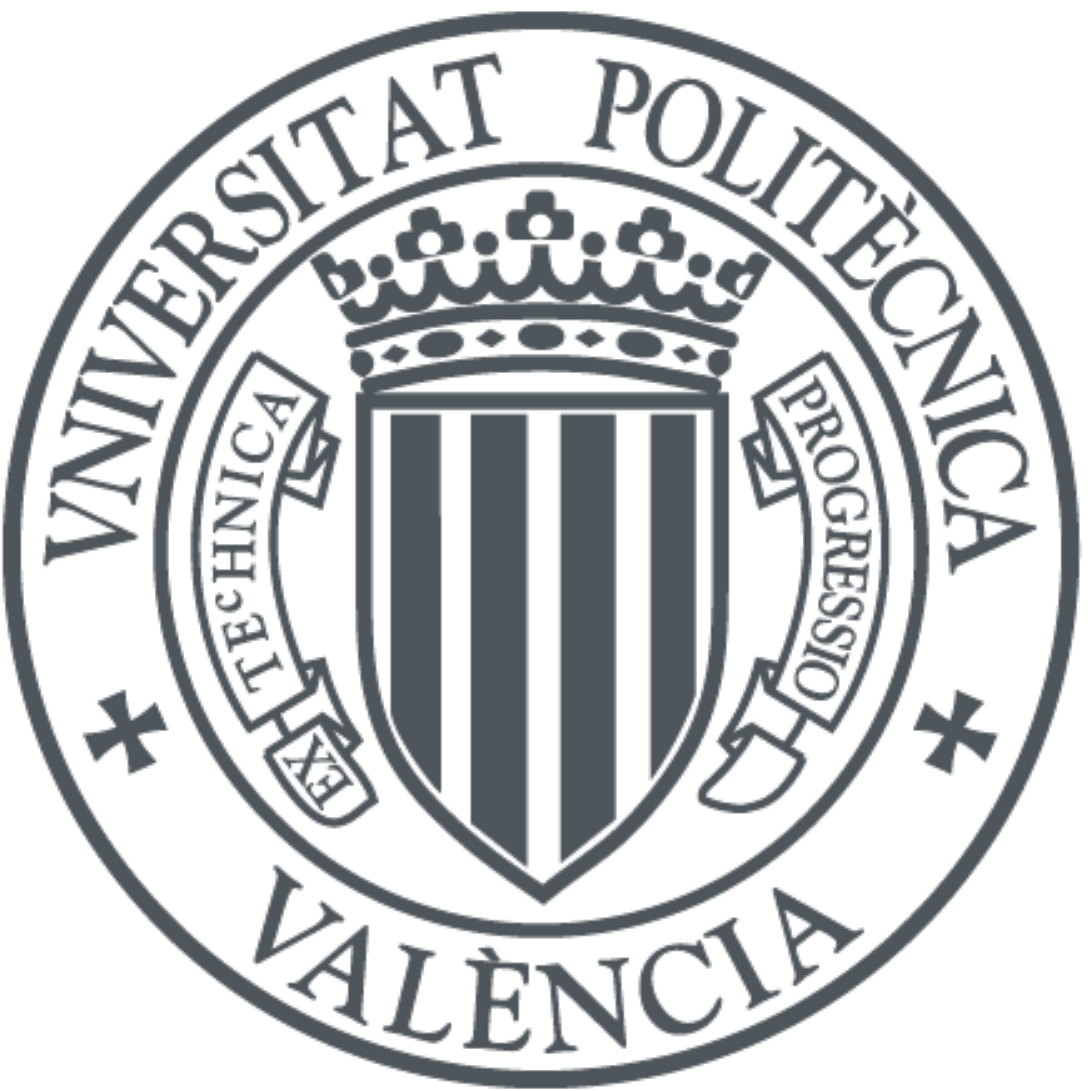

The final publication is available at

http://dx.doi.org/10.1016/j.memsci.2012.11.078

Copyright Elsevier

Additional Information 


\title{
Advanced control system for optimal filtration in submerged
}

\section{anaerobic MBRs (SAnMBRs)}

\author{
A. Robles ${ }^{\mathrm{a}, *}$, M.V. Ruano ${ }^{\mathrm{b}}$, J. Ribes $^{\mathrm{b}}$ and J. Ferrer ${ }^{\mathrm{a}}$
}

${ }^{\text {a } I n s t i t u t ~ U n i v e r s i t a r i ~ d ' I n v e s t i g a c i o ́ ~ d ' E n g i n y e r i a ~ d e ~ l ' A i g u a ~ i ~ M e d i ~ A m b i e n t, ~ I I A M A, ~}$ Universitat Politècnica de València, Camí de Vera s/n, 46022, Valencia, Spain (e-mail: ngerobma@upv.es; jferrer@hma.upv.es)

${ }^{\text {b }}$ Departament d'Enginyeria Química, Escola Tècnica Superior d'Enginyeria, Universitat de València, Avinguda de la Universitat s/n, 46100, Burjassot, Valencia, Spain (e-mail: m.victoria.ruano@uv.es; josep.ribes@uv.es)

* Corresponding author: tel. +34 9638799 61, fax +34 9638790 09, e-mail:

ngerobma@upv.es

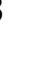

\section{Abstract}

The main aim of this study was to develop an advanced controller to optimise filtration in submerged anaerobic MBRs (SAnMBRs). The proposed controller was developed, calibrated and validated in a SAnMBR demonstration plant fitted with industrial-scale hollow-fibre membranes with variable influent flow and load. This 2-layer control system is designed for membranes operating sub-critically and features a lower layer (on/off and PID controllers) and an upper layer (knowledgebased controller). The upper layer consists of a MIMO (multiple-input-multipleoutput) control structure that regulates the gas sparging for membrane scouring and the frequency of physical cleaning (ventilation and back flushing). The filtration process is monitored by measuring the fouling rate on-line. This controller demonstrated its ability to keep fouling rates low (close to $0 \mathrm{mbar}^{\mathrm{min}}{ }^{-1}$ ) by applying sustainable gas sparging intensities (approx. $0.23 \mathrm{Nm}^{3} \mathrm{~h}^{-1} \mathrm{~m}^{-2}$ ). It also reduced the downtimes needed for ventilation and back-flushing (less than $2 \%$ of operating time). 


\section{Keywords}

Advanced control system; energy savings; industrial-scale hollow-fibre membranes;

knowledge-based controller; submerged anaerobic MBR

\section{Nomenclature}

Alk

$A n R$

$$
\boldsymbol{B}
$$

$B-1$

$B R F$

$B R F_{M A X}$

$B R F_{M I N}$

$B R F_{S P}$

$B R F_{S P}(t)$

$B R F_{S P}(t-C T)$

$\triangle B R F_{S P}$

c

CI

CIP

COD

$C O D_{S}$

$C O D_{T}$

CT

DV

$e F R_{C}$

$\triangle e F R C$

$\operatorname{AeFRC}(t)$

$\Sigma e F R C$

$\operatorname{seFRC}(t)$

$\operatorname{IeFRC}(t-C T)$

EPS carbonate alkalinity

anaerobic reactor

back-flush

biogas recycling blower

biogas recycling flow

maximum $B R F$

minimum BRF

set point $B R F$

$B R F_{S P}$ at sample time

$B R F_{S P}$ at previous sample time

modification in the BRF set point

centre of Gaussian membership function

confidence interval

clean in place

chemical oxygen demand

soluble $C O D$

total COD

control time

degasification vessel

error in $F R_{C}$

difference in $F R_{C}$

difference in fouling rate error at control time

accumulated error in $F R_{C}$

accumulated error in fouling rate at control time.

accumulated error in fouling rate at previous control time

extracellular polymeric substances 


\begin{tabular}{|c|c|c|}
\hline 1 & $F C$ & frequency converter \\
\hline 2 & $F C-P 11$ & rotating speed of permeate pump \\
\hline 3 & FC-P12 & rotating speed of sludge recycling pump \\
\hline 4 & FIT & flow indicator transmitters \\
\hline 5 & FIT-P11 & permeate flow \\
\hline 6 & $F I T-P 11_{S P}$ & permeate flow set point \\
\hline 7 & FIT-P12 & sludge flow entering membrane tank \\
\hline 8 & $F-R$ & filtration-relaxation \\
\hline 9 & $F R$ & fouling rate \\
\hline 10 & $F R_{C}$ & FR related to cake-layer formation \\
\hline 11 & $F R_{C}(t)$ & $F R_{C}$ at sample time \\
\hline 12 & $F R C_{-} S P$ & $F R_{C}$ set point \\
\hline 13 & $\boldsymbol{F} \boldsymbol{R}_{M}$ & intrinsic variation of $F R$ due to change in $J_{20}$ \\
\hline 14 & $F R_{M^{\prime}}(t)$ & $F R_{M}$ at sample time \\
\hline 15 & $\boldsymbol{F} \boldsymbol{R}_{T}$ & measured FR \\
\hline 16 & $F R_{T}(t)$ & measured FR at sample time \\
\hline 17 & $F S$ & flat sheet \\
\hline 18 & $H F$ & hollow fibre \\
\hline 19 & $H N$ & high negative \\
\hline 20 & $H P$ & high positive \\
\hline 21 & HRT & hydraulic retention time \\
\hline 22 & $H S^{-}$ & total sulphide expressed as $H S^{-}$ \\
\hline 23 & $J$ & transmembrane flux \\
\hline 24 & $J_{20}$ & $20^{\circ} \mathrm{C}$-normalised $\mathrm{J}$ \\
\hline 25 & $\Delta \boldsymbol{J}_{20}$ & change in $J_{20}$ \\
\hline 26 & $\left(\frac{\partial J_{20}}{\partial t}\right)$ & decrease in $J_{20}$ between two sample times \\
\hline 27 & $\left(\frac{\partial J_{20}}{\partial t}\right)_{M A X}$ & maximum decrease in $J_{20}$ \\
\hline 28 & $J_{20, M I N}$ & minimum $J_{20}$ \\
\hline 29 & $J_{20, M I N}(t)$ & $J_{20, M I N}$ at sample time \\
\hline 30 & $J_{20} S P$ & $J_{20}$ set point \\
\hline
\end{tabular}




\begin{tabular}{|c|c|c|}
\hline 1 & $J_{20 S P}(t)$ & $J_{20 ~ S P}$ at sample time \\
\hline 2 & $\% J_{20 S P}$ & maximum decrease in $J_{20}$ referred to the established $J_{20} S P$ \\
\hline 3 & $\% J_{20 S P}(t)$ & $\% J_{20 ~ S P}$ at sample time \\
\hline 4 & $J_{C}$ & critical flux \\
\hline 5 & $\boldsymbol{K}$ & permeability \\
\hline 6 & $K_{20}$ & $20^{\circ} \mathrm{C}$-normalised $\mathrm{K}$ \\
\hline 7 & $\% K_{20}$ & maximum decrease in highest $K_{20}$ recorded during filtration \\
\hline 8 & $K_{20, M A X, B F}$ & maximum back-flushing $K_{20}$ \\
\hline 9 & $K_{20, M A X, F}$ & maximum $K_{20}$ during filtration \\
\hline 10 & $K_{20, M I N}$ & minimum $K_{20}$ \\
\hline 11 & $K_{C}$ & controller gain \\
\hline 12 & $K_{M}, 20$ & intrinsic membrane permeability \\
\hline 13 & $L N$ & low negative \\
\hline 14 & $\boldsymbol{L P}$ & low positive \\
\hline 15 & $M B R$ & membrane bioreactor \\
\hline 16 & MIMO & multiple-input-multiple-output \\
\hline 17 & MLTS & mixed liquor total solids \\
\hline 18 & $M L T S_{A n R}$ & MLTS in AnR (MLTS entering MT) \\
\hline 19 & $M L T S_{M T}$ & $M L T S$ in $M T$ \\
\hline 20 & $M L T S_{M T, S P}$ & set point of MLTS returning to AnR \\
\hline 21 & $M T$ & membrane tank \\
\hline 22 & $N$ & negative \\
\hline 23 & $\mathrm{NH}_{4}-\mathrm{N}$ & ammonium measured as nitrogen \\
\hline 24 & $O L R$ & organic loading rate \\
\hline 25 & $O P C$ & OLE for process control \\
\hline 26 & $\boldsymbol{P}$ & positive \\
\hline 27 & $P-11$ & permeate pump \\
\hline 28 & $P-12$ & sludge recycling pump \\
\hline 29 & $P I D$ & proportional-integrative-derivative \\
\hline 30 & $P I T$ & pressure indicator transmitter \\
\hline 31 & $P L C$ & programmable logic controller \\
\hline
\end{tabular}




\begin{tabular}{|c|c|c|}
\hline 1 & $\mathrm{PO}_{4}-\mathrm{P}$ & orthophosphate measured as phosphorous \\
\hline 2 & $\boldsymbol{R}_{\boldsymbol{C}}$ & cake-layer resistance \\
\hline 3 & $\boldsymbol{R}_{I}$ & irreversible layer resistance \\
\hline 4 & $\boldsymbol{R}_{M}$ & membrane resistance \\
\hline 5 & $\boldsymbol{R}_{T}$ & total membrane resistance \\
\hline 6 & SAnMBR & submerged anaerobic $M B R$ \\
\hline 7 & $S C A D A$ & supervisory control and data acquisition \\
\hline 8 & $S D$ & standard deviation \\
\hline 9 & $S G D_{m}$ & specific gas demand per membrane area \\
\hline 10 & $S G D_{p}$ & specific gas demand per permeate volume \\
\hline 11 & SISO & single-input-single-output \\
\hline 12 & $S I T$ & solids concentration indicator transmitter \\
\hline 13 & $S M P$ & soluble microbiological products \\
\hline 14 & $\mathrm{SO}_{4-S}$ & sulphate measured as sulphur \\
\hline 15 & $S R F$ & sludge recycling flow \\
\hline 16 & $S R F_{M A X}$ & maximum SRF \\
\hline 17 & $S R F_{M I N}$ & minimum SRF \\
\hline 18 & $S R F_{S P}$ & SRF set point \\
\hline 19 & $S R T$ & sludge retention time \\
\hline 20 & $S T$ & sample time \\
\hline 21 & $T$ & temperature \\
\hline 22 & $T S$ & total solids \\
\hline 23 & $T S S$ & total suspended solids \\
\hline 24 & $t_{F, M A X}$ & maximum filtering time \\
\hline 25 & $\Delta t_{F R}$ & time interval used in FR calculations \\
\hline 26 & $T M P$ & transmembrane pressure \\
\hline 27 & $T M P(t)$ & TMP at sample time \\
\hline 28 & $T M P\left(t-\Delta t_{F R}\right)$ & $T M P$ at start of $\Delta t_{F R}$ \\
\hline 29 & $\Delta T M P$ & change in TMP \\
\hline 30 & $\triangle T M P_{M}$ & change in TMP associated with $K_{M, 20}$ due to a change in $J_{20}$ \\
\hline 31 & $\Delta T M P_{M},(t)$ & $\triangle T M P_{M}$, at sample time \\
\hline
\end{tabular}


1

2

3

4

5

6

7

8

9

10

11

12

13

14

15

16

17

18

19

20

21

22

23

24

25

26

27

28 maximum TMP

control action

ventilation

volatile fatty acids

volatile solids

volatile suspended solids

wastewater treatment plant

zero

minimum quantity of filtration phase data

amplitude of Gaussian membership function

modifying algebraic factor

permeate viscosity

degree of membership of input variable $p$

constant of integrative time

constant of derivative time

$t_{D}$

\section{Introduction}

In recent years there has been increased interest in the feasibility of using

SAnMBRs to treat municipal wastewater at ambient temperatures, focussing not only on the main advantages of MBRs (i.e. clarified and partially disinfected effluent; smaller environmental footprint of WWTPs) but also on the greater sustainability of anaerobic rather than aerobic processes: low sludge production due to the low anaerobic biomass yield, low energy consumption because no aeration is needed, and biogas generation that can be used as an energy resource.

MBRs usually operate at high MLTS levels which contribute to membrane fouling: one of the main handicaps of membranes [1]. Fouling reduces $\mathrm{K}$ and increases operating 
1 and maintenance costs [2]. In this respect, MBR installations still consume more energy

2 than conventional activated sludge systems, calling for further study into economical

3 and sustainability considerations [3]. Therefore, one key operating challenge of

4 SAnMBR technology is how membrane performance can be optimised whilst

5 minimising membrane fouling - in particular the irreversible/permanent component that

6 cannot be eliminated by chemical cleaning and ultimately determines the membrane

7 lifespan $[4,5,6]$.

8

9 One such fouling control strategy consists of operating membranes at sub-critical

10 filtration conditions [7] delimited by $J_{C}[8,9]$. On the other hand, in order to minimise

11 membrane fouling, a suitable physical and chemical membrane cleaning protocol must

12 be applied to given filtration conditions. Gas sparging intensity, usually measured as

$13 \mathrm{SGD}_{\mathrm{m}}$ or $\mathrm{SGD}_{\mathrm{p}}$, is one of the factors that affects $\mathrm{J}_{\mathrm{C}}$ most (at a specific MLTS level). The

14 gas sparging intensity in each operating range must, therefore, be optimised in order to

15 minimise membrane fouling and maximise energy savings in SAnMBR systems. It is

16 important to emphasise that aeration can account for up to $50-75 \%$ of all the energy

17 consumed by aerobic MBR technology [10]. Furthermore, minimising total operating

18 downtime whilst using other physical cleaning protocols (relaxation and back-flushing)

19 is a major challenge that must be solved if SAnMBR technology is to become

20 economically feasible.

Several studies published recently have theoretically analysed and experimentally validated the energy savings of different types of advanced control (mainly model-based or knowledge-based) in aerobic MBR technology. 
1 the efficiency of the filtration process in MBR technology by applying mathematical

2 models to enable appropriate action to increase permeability over time. Busch et al. [13]

3 proposed a model-based run-to-run (or run-by-run, batch-to-batch) process control

4 system that optimised the adjusted variables (filtration and back-flushing stages) after

5 each filtration cycle. However, the main drawback of such approaches is that the

6 complexity of the mechanisms involved makes it impossible to describe fouling exactly

7 or build a deterministic filtration model [14]. Due to the highly non-linear relations

8 found throughout the physical separation processes and the large number of filtration

9 mechanisms, the results achieved by model-based controllers are only acceptable when the process dynamics are bounded by a well-defined linear zone.

A variety of knowledge-based control laws, on the other hand, have been widely implemented in wastewater treatment in recent decades and been successful in several MBR applications. Huyskens et al. [3] validated an advanced knowledge-based control system that evaluated the reversible fouling propensity by using MBR-VITO (a specific on-line fouling measuring tool) [15]; Monclús et al. [16] developed and validated a knowledge-based control module for optimising MBR start-up procedures and minimising fouling; and Ferrero et al. [17, 18, 19] developed a knowledge-based control system to supervise filtration in aerobic MBRs, achieving considerable energy savings (up to $21 \%$ ) in membrane scouring.

Several simple operating strategies to control membrane fouling instead of advanced controllers have been experimentally validated. Jeison and van Lier [20] developed an on-line cake-layer management protocol that monitored critical flux constantly and prevented excessive cake-layer from building up on the membrane surface; Smith et al. [21] developed a control system to optimise back-flushing which 
1 reduced the water needed for back-flushing by up to 40\%; Vargas et al. [22] established

2 a control algorithm for fouling prevention which regulated back-flushing by constantly

3 measuring TMP and J; and Park et al. [23] studied how membrane fouling could be

4 reduced by successively increasing and decreasing the gas sparging intensities, and

5 recorded the effectiveness in reducing membrane fouling.

6

7

Nevertheless, further study is required into control strategies of this type (designed to save energy in SAnMBR technology on an industrial scale) due to the lack of knowledge about fouling in anaerobic MBRs. In this respect, knowledge-based controllers may be a powerful tool for filtration control in SAnMBR technology because they are easily applied to non-linear processes. Fuzzy-logic controllers [24] in particular can optimise a variety of processes in dynamic operating and loading conditions by applying valuable expert knowledge [25, 26, 27]. In addition, control strategies of this type do not require a large amount of data and/or a rigorous mathematical model, and also allow MIMO control schemes to be developed.

To gain more insight into the optimisation of a SAnMBR system on an industrial scale, we designed a new control approach to minimise energy consumption during subcritical filtration in a SAnMBR demonstration plant. To obtain representative results that could be extrapolated to full-scale plants, the SAnMBR system featuring industrial HF membrane units was operated using effluent from the pre-treatment of the Carraixet WWTP (Valencia, Spain). The main aim was to design a competitive and feasible control system capable of enhancing filtration in industrial-scale SAnMBR systems with minimum operating costs. This advanced control system was developed taking advantage of the industrially feasible on-line sensors now available for monitoring key physical variables in filtration processes (i.e. pressure, flow and total solids). 


\section{2. Materials and methods}

3

4 2.1. SAnMBR plant description

5

6

Figure 1 shows a simplified lay-out of the SAnMBR plant used in this study

7 including the main instrumentation and controllers. The plant consists of an anaerobic

8 reactor with a total volume of $1.3 \mathrm{~m}^{3}\left(0.4 \mathrm{~m}^{3}\right.$ head space for biogas) connected to two

9 membrane tanks each with a total volume of $0.8 \mathrm{~m}^{3}\left(0.2 \mathrm{~m}^{3}\right.$ head space for biogas).

10 Each membrane tank (MT) has one industrial HF ultrafiltration membrane unit

11 (PURON $^{\circledR}$, Koch Membrane Systems (PUR-PSH31) with $0.05 \mu \mathrm{m}$ pores). Each module

12 has a total membrane surface of $30 \mathrm{~m}^{2}$. To recover the bubbles of biogas in the permeate

13 leaving the membrane tank, two degasification vessels (DV) were installed: one

14 between each MT and the respective vacuum pump. The funnel-shaped section of conduit makes the biogas accumulate at the top of the DV. The resulting permeate is stored in the CIP tank. The two parallel membrane tanks make plant operating very flexible because it can work with one membrane tank or the other or both. Moreover, each tank enables the resulting permeate to be constantly recycled back into the anaerobic reactor, enabling different transmembrane fluxes to be tested without affecting HRT. The filtration results given in this paper are experimental data obtained from a membrane tank constantly recycling permeate back into the system. The HRTs tested to assess biological performances were, therefore, obtained from another membrane tank running in parallel. membrane operating stages (filtration, relaxation and back-flushing) but also 
1 ventilation. In the ventilation stage, permeate is pumped into the membrane tank

2 through the degasification vessel instead of through the membrane. The aim of

3 ventilation is to recover the biogas that accumulates in the degasification vessel. Thus,

4 in terms of membrane cleaning, ventilation acts as a relaxation since no transmembrane

5 flux is applied whilst maintaining a given gas sparging intensity.

6

7

For further details about this SAnMBR system, see Giménez et al. [28] and Robles

8 et al. [7].

9

\subsection{Monitoring system description}

11

Many on-line sensors and automatic devices were installed in order to automate and control plant operating and provide on-line information about the state of the process (see Figure 1). All instrumentation is labelled according to the name of the tank or equipment (i.e. pump or blower) where the sensor is installed. The main features of the installed equipment are: on-line availability and industrial feasibility, low-cost, corrosion resistance, long lifespan, and low and easy maintenance. The instrumentation is connected to a network system featuring several transmitters, a PLC and a PC to perform multi-parameter control and data acquisition. Both the operating data logging and the plant control are carried out by a SCADA system installed in the PC, which centralises all the signals from the sensors and actuators installed in the plant. In addition, the SCADA is linked to an OPC system that enables communication with external dedicated applications featuring upper-layer controllers.

\section{The group of on-line sensors used in this study, shown in Figure 1, consists of the} following: one solids concentration indicator transmitter (Hach Lange model TSS EX1 
1 sc), MLTS ${ }_{\text {AnR }}$, located in the anaerobic reactor; two flow indicator transmitters

2 (Endress+Hauser model Proline Promag 50), FIT-P11 and FIT-P12, i.e. one for the

3 permeate pump (JUROP VL02 NBR, P-11) and another for the mixed liquor feed pump

4 (CompAir NEMO, P-12); one flow indicator transmitter (Iberfluid model VORTEX

5 84F), FIT-B1, for the membrane tank blower (FPZ 30HD, B-1); one pH-temperature

6 sensor (Endress+Hauser model Liquiline M pH-ORP CM42), pHT-MT, located in the

7 membrane tank; and one liquid pressure indicator transmitter (Endress+Hauser model

8 Cerabar M PMC41), PIT-P11, to monitor the TMP. The group of actuators used in this

9 study consists of a group of on/off flow-direction valves to control the different

The composition of the biogas $\left(\mathrm{CH}_{4}, \mathrm{CO}_{2}, \mathrm{H}_{2}\right.$ and $\left.\mathrm{H}_{2} \mathrm{~S}\right)$ was measured online using an X-STREAM enhanced analyser (EMERSON PROCESS Analytical GmbH). This equipment combines four measuring channels: two non-dispersive infrared channels for measuring $\mathrm{CH}_{4}$ and $\mathrm{CO}_{2}$; one thermal conductivity channel for measuring $\mathrm{H}_{2}$; and one non-dispersive ultraviolet channel for measuring $\mathrm{H}_{2} \mathrm{~S}$.

\subsection{Sampling and analytical monitoring}

The performance of the biological treatment was assessed by taking 24-hour composite samples of influent and effluent plus grab samples of biogas and anaerobic sludge once a day. The following parameters of influent, effluent and anaerobic sludge were analysed: TS, VS, TSS, VSS, VFA, Alk, $\mathrm{SO}_{4}-\mathrm{S}$, total sulphide (expressed as $\mathrm{HS}^{-}$), 
nutrients $\left(\mathrm{NH}_{4}-\mathrm{N}\right.$ and $\left.\mathrm{PO}_{4}-\mathrm{P}\right)$, and $\mathrm{COD}_{\mathrm{T}}$ and $\mathrm{COD}_{\mathrm{S}}$.

Levels of solids, COD, sulphate, total sulphide and nutrients were determined by Standard Methods [29], and Alk and VFA levels by titration according to the method proposed by WRC [30].

\subsection{Operating conditions}

The SAnMBR plant in this study was fed with effluent from the pre-treatment phase of a full-scale urban WWTP (screening, degritter and grease removal). Table 1 shows the average properties of this influent wastewater. This highlights its significant sulphate content in comparison with typical domestic wastewater, and also the wide variation in influent loads as shown by the high standard deviation of each parameter.

The uncertainty of each value takes into account both the SD of the different samples analysed and the variation coefficient of the analytical methods. Table 1 also shows the median, minimum and maximum values and $95 \% \mathrm{CI}$.

During the 3-year experimental period, the plant was operated continuously under a variety of operating conditions to study the biological process performance: SRT ranged from 20 to 70 days; HRT ranged from 5 to 24 hours, resulting in OLR of 0.5 to 2 $\operatorname{kgCOD~m} \mathrm{m}^{-3}$; and temperatures, from 14 to $33^{\circ} \mathrm{C}$.

\section{Advanced control system description}

The proposed controller aims to optimise the filtration process in a SAnMBR system, maintaining sub-critical filtration conditions and minimising operating costs. In 
1 this respect, this control system aims to operate membranes at fouling rates close to zero

2 by modifying not only the gas sparging intensity for membrane scouring in the

3 membrane tank, but also the starting time and frequency of both ventilation and back-

4 flushing.

5

6

As Figure 1 shows, the proposed control system consists of a combination of 5

7

\subsection{Lower-layer controllers}

The group of lower-layer controllers used in this study, shown in Figure 1, consists of the following: three PID controllers to adjust the rotating speed of the sludge recycling pump (P-12), the permeate pump (P-11) and the biogas recycling blower (B1) by the corresponding frequency converter (FC-P12, FC-P11 and FC-B1 respectively) in order to keep the corresponding flow close to its set point value; one on-off controller that determines the membrane operating stage by changing both the position of the corresponding on-off valves and the flux direction of the permeate pump; and one proportional controller that determines the $\mathrm{SRF}_{\mathrm{SP}}$ through the membrane tank depending on the FIT-P11sP and the MLTS in the anaerobic reactor (measured by

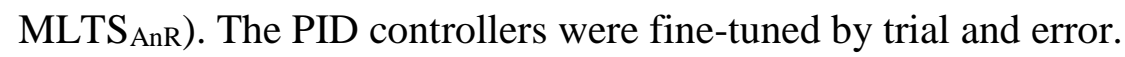


The aim of the proportional controller is to reduce the energy consumption of both

3 sludge and permeate pumping. When the anaerobic reactor is operated at high MLTS

4 levels, the SRF must be high enough not only to maintain suitable levels of MLTS in

5 the membrane tank, but also to minimise the energy consumed by permeation. It must

6 be emphasised that, depending on the sludge concentration factor (the ratio between the

7 sludge flow entering the membrane tank and the net permeate flow), the MLTS in the

8 membrane tank could reach prohibitive levels. It must also be said that MLTS is a key

9 operating factor as regards membrane permeability [31] which therefore affects the energy required for permeate pumping. Nonetheless, SRF must be minimised in order to maximise energy savings since sludge pumping energy accounts for $15-20 \%$ of all the energy consumed by aerobic MBR technology [10]. Hence, it is advisable for SRF to be regulated in order to optimise the economic feasibility of full-scale SAnMBR systems. Therefore, the proposed advanced control system features a control strategy based on proportional action taking into account both the MLTS entering the membrane tank and the permeate flux. balance (MLTS mass balance) to the membrane tank (see Eq. 1). The left and right sides of Eq. 1 are the input and output terms of the mass balance, respectively. In this mass balance, the effluent MLTS concentration is assumed to be zero (see second term on the right side of Eq.1). Accumulation and generation terms are not considered.

$$
M L T S_{A n R} \cdot S R F=M L T S_{M T} \cdot(S R F-F I T-P 11)+0 \cdot F I T-P 11
$$


2 given MLTS $\mathrm{MT}_{\mathrm{MTP}}$ as a function of the recorded values of MLTS $_{\mathrm{AnR}}$ and FIT-P11 (see

3 Eq. 2).

4

$5 \quad \mathrm{SRF}_{\mathrm{SP}}=\frac{\mathrm{FIT}-\mathrm{P} 11 \cdot \mathrm{MLTS}_{\mathrm{MT}, \mathrm{SP}}}{\mathrm{MLTS}_{\mathrm{MT}, \mathrm{SP}}-\mathrm{MLTS}_{\mathrm{AnR}}}$

6

$7 \quad \mathrm{SRF}_{\mathrm{SP}}$ was only modified within a pre-defined range delimited by the minimum and

8 maximum flows provided by the sludge recycling pump: $\operatorname{SRF}_{M I N}\left(1.0 \mathrm{~m}^{3} \mathrm{~h}^{-1}\right)$ and

$9 \operatorname{SRF} \operatorname{MAX}\left(2.7 \mathrm{~m}^{3} \mathrm{~h}^{-1}\right)$, respectively.

10

\subsection{Upper-layer controller}

12

The flow chart of the proposed upper-layer controller (Figure 2) shows how this upper-layer controller is divided in three subsections: (i) initialisation where the control variables are calculated; (ii) a preliminary group of knowledge-based rules; and (iii) a fuzzy-logic controller. As mentioned before, this control system aims to operate membranes sub-critically, keeping the fouling rate close to zero. Basically, the fouling rate is controlled by adjusting the BRF through the membrane tank by means of the fuzzy-logic controller, and the membrane operating stage (filtration, ventilation or backflushing) by the preliminary knowledge-based rules. In addition to the FR, the control

21 variables of this MIMO control structure are TMP, K and J. 
1 Control variables TMP and J were calculated by a 15 second, mobile average in

2 order to filter the typical signal noise from the corresponding sensors (ST set to 5

3 seconds). Therefore, a minimum quantity of filtration phase data ( $\left.\mathrm{Z}_{\mathrm{MIN}}\right)$ was needed to

4 calculate the control parameter. The $J_{20}$ was calculated using Eq. 3 in order to reflect the

5 dependence of $\eta$ on $\mathrm{T}$, and the $K_{20}$ was calculated using a simple filtration model (Eq. 4)

6 that takes into account the TMP and $\mathbf{J}_{20}$ data monitored on-line. In this classic filtration

7 model, $R_{T}$ was theoretically represented by $R_{M}, R_{I}$, and $R_{C}$.

8

$9 \quad J_{20}=J_{T} \cdot e^{-0.0239(T-20)}$

$10 \quad K_{20}=\frac{1}{\eta \cdot R_{T}}=\frac{1}{\eta \cdot\left(R_{M}+R_{I}+R_{C}\right)}=\frac{J_{20}}{T M P}$

As regards the control variable, i.e. the fouling rate, several techniques to monitor membrane fouling are described in literature. In most of them, however, membrane

14 fouling cannot be measured on-line because they are too invasive and require

15 subsequent chemical cleaning, or require new instrumentation which increases their

16 operating costs [32]. In our study membrane fouling was measured on-line as the

17 change in TMP over time (Eq. 5).

$F R_{T}(t)=\frac{\Delta \mathrm{TMP}}{\Delta t}=\frac{T M P(t)-T M P\left(t-\Delta t_{F R}\right)}{\Delta t_{F R}}$

From Eq. 4 it can be assumed that any change in $J_{20}\left(\Delta J_{20}\right)$ results in a proportional 22 change in TMP $(\triangle T M P)$ when treating clean water. In this case, $K_{M^{\prime}, 20}$ can be assumed 23 to be constant and proportional to the sum of both the membrane and irreversible 
1 fouling resistances in series (see Eq. 6). Membrane and irreversible fouling resistances

2 can be assumed to be constant because the tortuosity of both the membrane and the

3 irreversible fouling layer is not expected to increase due to pressure in low-pressure

$4 \quad$ filtration processes.

5

$6 \quad K_{M^{\prime}, 20}=\frac{1}{\eta \cdot\left(R_{M}+R_{I}\right)}=\frac{\Delta J_{20}}{\Delta T M P}$

7

8 On the basis of this assumption, the fouling rate calculated by Eq. 5 was not

9 adopted as the control variable of the control system. The control variable adopted was

$10 \quad \mathrm{FR}_{\mathrm{C}}$ calculated by Eq. 7. The intrinsic variation of the fouling rate caused by a change in

$11 \mathbf{J}_{20}$ was not considered in order to minimise the total energy consumption since this

12 fouling rate component cannot be remedied/minimised by increasing BRF. FR $_{C}$ variable

13 is obtained from the total measured fouling rate (Eq. 5) and the intrinsic variation of the

14 fouling rate due to a change in $\mathrm{J}_{20}\left(\mathrm{FR}_{\mathrm{M}}, \mathrm{Eq} .8\right)$.

15

$16 \quad F R_{C}(t)=F R_{T}(t)-F R_{M \prime}(t)$

17

$18 \quad F R_{M \prime}(t)=\frac{\Delta T M P_{M \prime}(t)}{\Delta t_{F R}}$

19

20

In order to calculate $\triangle T M P_{M}$, using Eq. $6, K_{M^{\prime}, 20}$ must be estimated. This is done by using the simple filtration model given in Eq. 4 during back-flushing, determining the maximum back-flushing permeability, i.e. $K_{20, M A X, B F}$ which is considered to be the

23 maximum filtering permeability of the membrane under study. This assumption is based

24 on the fact that after a significant back-flushing period, cake layer resistance is 
1 negligible, and the resulting membrane resistance is the sum of both membrane and

2 irreversible fouling resistances. This permeability is therefore calculated when the TMP

3 during back-flushing remains stable over time at a given J. This calculation is done once

4 a day when the maximum filtering time ( $\left.t_{F, M A X}\right)$ is reached (see Figure 2$)$. This

5 maximum filtering time (set to 1 day in this study) is defined in order to apply at least

6 one back-flush per day, when the filtration stage is not interrupted by other conditions

7 defined in the control system.

8

9 Calculating maximum back-flushing permeability is an useful way of monitoring the reduction in permeability during long-term membrane operating and deciding the right

11 time to conduct chemical membrane cleaning or recovery.

12

In addition to $K_{20, M A X, B F}, K_{20, M A X, F}$ was another input variable for the preliminary

14 knowledge-based rules. This variable was defined as the maximum $K_{20}$ calculated by

15 Eq. 4 during each filtration stage.

16

Thus, as Figure 2 shows, the first subsection of the flow chart (i) represents all the calculations needed to obtain the final values of the control variables at each CT: FR

$19 \mathrm{~K}_{20}$, TMP and $\mathrm{J}_{20}$. In this study, CT was set to 20 seconds.

20

3.2.2. Preliminary knowledge-based rules

22

Similar to Vargas et al. [22], different knowledge-based rules have been included in the proposed advanced control system. The aim of these control rules was to decide when to initiate both ventilation (also acting as relaxation) and back-flushing. An 
1 additional rule designed to determine the right time for the chemical cleaning or

2 recovery of membranes was also taken into account.

3

4 As Figure 2 shows (subsection ii), at each time interval between two control actions

5 (CT), the control system applies the different knowledge-based rules to decide whether

6 or not to start ventilation or back-flushing.

7

8 3.2.2.1. Ventilation initiation

9

25 permeate.
As mentioned above, the aim of ventilation is to recover the biogas that accumulates in the degasification vessel thus reducing the amount of methane expelled with the effluent. For this reason, a degasification vessel was installed in the membrane tank. This degasification vessel accumulates the biogas released from the extracted

Ventilation takes place when the system detects that some of the biogas accumulated in the degasification vessel is extracted with the effluent during filtration. This is revealed by the rotating speed of the permeate pump suddenly increasing to its maximum operating value without reaching the permeate flow set point. Ventilation is activated at this stage in order to recover the biogas remaining in the degasification vessel by recycling it into the membrane tank. As mentioned before, ventilation causes membrane permeability to fall to previous values because it acts as relaxation in terms of membrane physical cleaning. The corresponding control action is expressed by Rule 1 .

$I F\left[J_{20}(t)<J_{20, M I N}(t)\right] A N D\left[\left(\frac{\partial J_{20}}{\partial t}\right)>\left(\frac{\partial J_{20}}{\partial t}\right)_{M A X}\right]$ THEN [Ventilation stage $]$ (Rule 1) 


\subsubsection{Back-flushing initiation}

7

8 Back-flushing minimises the long-term build-up of a reversible cake layer on the

9 membrane surface. Two different rules for back-flushing initiation were defined in the 10 proposed advanced control system: (1) when membrane permeability is below a

11 minimum value (Rule 2); and (2) when a maximum TMP value (Rule 3) is reached.

$T M P_{M A X}$ was set to 450 mbar in our study. 
1 recycling flow (i.e. $\triangle B R F_{S P}$ ) on the basis of three inputs obtained from the estimated

2 fouling rate caused by cake-layer formation, i.e. error (Eq. 11), accumulated error (Eq.

3 12) and error difference (Eq. 13). The structure of this controller is, therefore, a fuzzy

$4 \quad$ version of the classical PID.

5

$6 \quad e F R_{C}(t)=F R_{C}(t)-F R_{C_{-} S P}$

7

$8 \quad \sum e F R_{C}(t)=\Sigma e F R_{C}(t-C T)+C T \cdot e F R_{C}(t)$

9

10

$\Delta e F R_{C}(t)=\mathrm{e} F R_{C}(t)-\delta \cdot \mathrm{e} F R_{C}(t-C T)$

11

The fouling rate error difference variable calculated by Eq. 13 will be negative or

positive depending on whether or not the fouling rate error tends to zero because this equation features a modifying algebraic factor $(\delta)$ which is defined in Eq. 14.

$16 \delta=\frac{e F R_{C}(t) \cdot e F R_{C}(t-C T)}{\left|e F R_{C}(t) \cdot e F R_{C}(t-C T)\right|}$

17

18

19

20

21

22

23

24

25

Although a classical PID controller could have been used, the fuzzy-logic based controller was preferred because of strong non-linear relations between the input and output of the filtering process (several factors affect membrane performance considerably). Fuzzy-logic controllers are suitable for systems which are extremely nonlinear and also for processes that are too complex to be analysed using conventional quantitative techniques or when available sources of information are subjective, inexact or unreliable. Well-developed fuzzy logic controllers can generalise to a great extent and can easily be developed and fine-tuned by an experienced plant operator because 
1 fuzzy logic is much closer to human reasoning and natural language than traditional

2 control algorithms.

3

$4 \quad$ 3.2.4. Description of fuzzy-logic controller structure

5

6

The fuzzy-logic controller has five stages. In the first stage the input variables

$7 \quad\left(e F R_{C}, \Delta e F R_{C}\right.$ and $\left.\sum e F R_{C}\right)$ are calculated from the estimated fouling rate due to cake-

8 layer formation (see Eq. 11 to 13). Once the input variables are calculated, in the

9 fuzzification stage (stage 2) the input variables are converted into linguistic variables

10 (fuzzy set) represented by membership functions. The proposed controller used

11 Gaussian membership functions (see Eq 15) because they produce smooth controller

12 output. Three Gaussian membership functions were considered for each input: $N, Z$ and

$13 P$.

14

$15 \mu(p)=\exp \left(-\frac{(p-c)^{2}}{2 \cdot \sigma^{2}}\right)$

16

17

The output variable of the controller is $\Delta B R F_{S P}$. In the defuzzification stage of this output variable, four singleton membership functions were defined as output linguistic variables: $H N, L N, L P$ and $H P$.

In stage 3, the inference engine, a set of rules is applied to the fuzzy sets obtained in stage 2 . Table 2 shows the inference rules defined for the proposed fuzzy-logic controller. As Table 2 shows, each inference rule consists of an if-then fuzzy implication. Each inference rule is built by the fuzzy intersection $(A N D)$ of two input fuzzy sets $(N, Z, P)$ from the input variables $\left(e F R_{C}, \Delta e F R_{C}, \Sigma e F R_{C}\right)$. Each fuzzy 
1 intersection results in one fuzzy output set $(H N, L N, L P, H P)$ for the output variable

$2\left(\triangle B R F_{S P}\right)$. The degree of membership $(\mu)$ of each input fuzzy set is given by the

3 corresponding Gaussian membership function in the range [0, 1]. When $\mu$ is zero, the

4 corresponding rule is inactive and does not contribute to the output.

5

6 Because the proposed filtration control system is hierarchical, the priorities for 7 applying Table 2 rules are different from those of the preliminary group of knowledge-

8 based rules. The filtration control system prioritises the preliminary group of

9 knowledge-based rules, so when a knowledge-based rule is initiated the controller is initialised and no fuzzy-logic controller action is applied (see Fig. 2, subsection ii).

11 Otherwise, when no knowledge-based rule is initiated, Table 2 rules are applied (see 12 Fig. 2, subsection iii).

13

The output linguistic variables (fuzzy output sets) were obtained in this stage by applying Larsen's fuzzy inference method [33] using the Max-Prod operator. Hence, for each rule defined in Table 2, the operator represented by Eq. 16 was applied (where $i$ represents each inference rule defined and $j$ represents each of the input fuzzy sets in rule $i$ ).

$\mu_{i}=\prod_{1}^{j} \mu_{j}$

The operator expressed in Eq. 17 (where $k$ represents each of the linguistic variables defined for the output variable) was then applied to establish just one linguistic output value when the consequences of different rules are the same (i.e. the consequence results in the same linguistic output variable). 
$1 \quad \mu_{k}=\operatorname{Max}\left(\mu_{i}\right)$

(Eq. 17)

2

During defuzzification (stage 4), linguistic variables are converted into the

4 corresponding numerical control actions. Hence, in order to obtain a single output value

5 from the fuzzy linguistic set, the Height Defuzzifier method [34] was employed (see Eq.

$6 \quad 18)$.

7

$8 \Delta B R F_{S P}(t)=\frac{\Sigma\left(c_{k} \cdot \mu_{k}\right)}{\Sigma\left(\mu_{k}\right)}$

9

Finally, stage 5 is the output stage where the numerical control action of the fuzzy-

11 logic controller is obtained, i.e. the set point of the biogas recycling flow. The control action of the fuzzy logic controller is expressed by Eq. 19, giving the integral output action necessary for set-point tracking.

14

$B R F_{S P}(t)=B R F_{S P}(t-C T)+\triangle B R F_{S P}(t)$

16

The biogas recycling flow was only modified within a defined range to avoid operating problems, taking into account the following constraints: the minimum biogas recycling flow needed for the membranes to operate and the maximum biogas recycling flow provided by the blower. These are $B R F_{M I N}\left(5.5 \mathrm{Nm}^{3} \mathrm{~h}^{-1}\right.$, i.e. an $\mathrm{SGD}_{\mathrm{m}}$ of $0.18 \mathrm{Nm}^{3}$ $\left.\mathrm{h}^{-1} \mathrm{~m}^{-2}\right)$ and $B R F_{M A X}\left(11 \mathrm{Nm}^{3} \mathrm{~h}^{-1}\right.$, i.e. an $\mathrm{SGD}_{\mathrm{m}}$ of $\left.0.37 \mathrm{Nm}^{3} \mathrm{~h}^{-1} \mathrm{~m}^{-2}\right)$, respectively.

\section{Results and discussion}


1 used the standard dry weather influent records (updated in 2006) recommended by Copp

2 [35] which are generally accepted for evaluating control algorithms in WWTPs. The

3 influent flow dynamics were calculated by applying a dynamic peak flow factor

4 (calculated on the basis of the above-mentioned influent file) to an influent flow base of

$5225 \mathrm{~L} \mathrm{~h}^{-1}$. The permeate flow was then set using the same time-series behaviour as for

6 the influent.

7

8

The influent flow base $\left(225 \mathrm{~L} \mathrm{~h}^{-1}\right)$ was established on the basis of the lifetime of the membranes used. It is important to emphasise that the proposed control system was calibrated and validated using a two-and-a-half-year-old membrane. Permeability was expected to be low because this membrane was used constantly and never underwent any physical or chemical cleaning.

\subsection{Performance of sludge recycling flow controller}

Figure 3 illustrates the performance of the sludge recycling flow controller during one day of operation (day 16). This figure shows the evolution of SRFSP and SRF throughout the membrane tank, FIT-P11 and FIT-P11sP, and FC-P12.

As Figure 3 shows, SRF was adjusted proportionately to permeate flow. In this operating period MLTS $_{\mathrm{AnR}}$ remained almost constant, varying from around 17.2 to 17.5 $\mathrm{g} \mathrm{L}^{-1}$, whilst MLTS $\mathrm{MT}$,SP was set to $20 \mathrm{~g} \mathrm{~L}^{-1}$. From hours 3 to 9 , and 10.5 to 11.5 , the minimum rotating speed for the sludge recycling pump and maximum SRF were reached, respectively. Therefore, the controller was not able to set the SRF to the expected set point. Nevertheless, the controller generally allowed MLTS to remain close to its set point in the membrane tank (checked by the corresponding lab measurements), 
1 thereby enabling an overall reduction in the energy consumed during filtration.

2

3

$4 \quad$ SRF of $1.7 \mathrm{~m}^{3} \mathrm{~h}^{-1}$ ) with those obtained when operating at a set SRF of $2.7 \mathrm{~m}^{3} \mathrm{~h}^{-1}$, energy

5

6

7

8

10

For instance, for our case study, comparing the results shown in Figure 3 (average savings of up to $50 \%$ are obtained in sludge pumping (calculated theoretically using the classical mechanical energy balance). This means that the energy demand for sludge pumping could be reduced from approximately 0.06 to $0.03 \mathrm{kWh} \mathrm{m}^{-3}$.

\section{4.2. Performance of knowledge-based rules}

As mentioned before, the aim of the knowledge-based rules is to determine the best time to start ventilation and back-flushing.

\subsubsection{Ventilation initiation}

Figure 4 shows how the knowledge-based rule concerning ventilation initiation performed on one operating day (day 16). Figure 4a shows FIT-P11 1 sP and the membrane operating mode. Figure $4 \mathbf{b}$ shows the recorded $\mathbf{J}_{20}$ and $\mathbf{J}_{20, S P}, \mathbf{J}_{20, \mathrm{MIN}}$, and FCP11.

Figure $4 \mathrm{a}$ shows how ventilation frequency increases as permeate flow increases.

This increase in ventilation frequency is related to the amount of biogas in the permeate leaving the system. In this respect, the higher the permeate flow, the greater the amount of biogas extracted. Therefore, ventilation frequency increases in order to recover as much biogas as possible from the top of the degasification vessel. No ventilation was conducted between hours 4 and 9 approximately due to the lower vacuum strength 
1 applied for filtration (i.e. low transmembrane fluxes were applied), resulting in little

2 biogas being extracted with the effluent. On the other hand, it must be emphasised that

3 each ventilation stage constituted a relaxation stage in terms of membrane scouring,

4 resulting in a partial improvement in membrane permeability.

5

6 Figure $4 \mathrm{~b}$ shows the ventilation initiation times calculated by the respective

7 knowledge-based rule. As mentioned before, the controller triggers ventilation when a

8 sharp increase in the rotating speed of the permeate pump is detected but the

9 corresponding $\mathbf{J}_{20}$ set point is not maintained. This situation was observed 24 times

during the operating period shown in Figure 4. It is important to emphasise that Figure 4

11 illustrates the higher ventilation frequency observed throughout the experimental period

12 that includes controller validation. This frequency means a ventilation downtime of

13 around $1.4 \%$ of operating time. This value is considerably lower than the average full-

14 scale results from aerobic MBR technology found in literature. For instance, Judd and

15 Judd [1] reported a relaxation downtime of around 10\% of the operating time in both FS

16 and HF configurations. Therefore, considerable energy savings may be achieved by

17 using the rule-based controller rather than the fixed membrane operating sequences

18 provided by membrane suppliers.

\subsubsection{Back-flushing initiation}

Figure 5 shows how the knowledge-based rules concerning the start of back-

23 flushing performed during one day of operation (day 16). Figure 5a shows TMP,

24 TMP ${ }_{\text {MAX }}$ and membrane operating mode. Figure $5 b$ shows $\mathrm{K}_{20, \mathrm{MAX}, \mathrm{F}}$ and $\mathrm{K}_{20, \mathrm{MIN}}$, and

$25 \mathrm{~K}_{20}$ calculated over time using on-line T, TMP and J data. 
Figure 5a shows three back-flushing starts during the experimental period. Rule 2 was applied at hours 2.7 and 12 . As Figure $5 \mathrm{~b}$ shows, $\mathrm{K}_{20}$ declined considerably (35\%) during filtration, which triggered back-flushing. On the other hand, Rule 3 triggered back-flushing at hour 11.5 because the maximum TMP set for membrane operation (0.45 bars) had been reached.

Hence, as Figure 5 shows, back-flushing downtime accounted for around $0.2 \%$ of operating time. Similar results were observed throughout the experimental period in which controller validation took place. This downtime is also considerably lower than the average results reported for full-scale aerobic MBR technology in literature, i.e. back-flushing downtime of around $6-9 \%$ of operating time dedicated to treating urban wastewater aerobically [1]. This gives a total average downtime for physical cleaning (relaxation and back-flushing) of around $16-19 \%$ of operating time when using HF technology to treat urban wastewater aerobically (instead of the downtime of approx. 1.6\% obtained in the period shown in Figures 4 and 5).

\subsection{Performance of fuzzy-logic controller}

An example of how the control system performed after calibration (day 16) is shown in Figure 6. The fuzzy-logic controller was adjusted by means of the classic trial and error method.

$$
\text { Figure 6a illustrates the evolution of FIT-P11 and FIT-P11 SP (fixed by the dry }
$$
weather influent dynamics records proposed by Copp), and also BRF and BRF resulting from the control action. Figure $6 \mathrm{~b}$ also shows $\mathrm{BRF}$ and $\mathrm{BRF}_{\mathrm{SP}}$, plus $\mathrm{FR}_{\mathrm{C}}$ and $\mathrm{FR}_{\mathrm{C} \_ \text {SP. }}$ The fouling rate set point was set to $0 \mathrm{mbar}^{\mathrm{min}}{ }^{-1}$ in order to keep filtration 
conditions sub-critical.

As can be observed in Figure 6, a fast controller response was achieved to compensate the fouling rate error (see, for instance, hours 20 to 24). In this respect, even when a dynamic influent flow set point was applied, the control response was able to keep the controlled variable close to the established set point by modifying BRF.

As Figure $6 b$ shows, the controller operated mainly at the minimum threshold value established for $\operatorname{BRF}\left(5.5 \mathrm{Nm}^{3} \mathrm{~h}^{-1}\right)$ as, for instance, in hours 2 to 7 . In this period an excessive gas sparging intensity could have been applied for membrane scouring because the minimum BRF was reached. Between hours 9 to 12, on the other hand, BRF reached its maximum established value $\left(11 \mathrm{Nm}^{3} \mathrm{~h}^{-1}\right)$. During this period the fouling rate increased because it was not possible to maintain the controlled variable around its set point. This behaviour can be also observed from hours 20 to 24 . In this situation, it can be assumed that critical filtration conditions were exceeded. It must once again be emphasised that the controller was validated using a two-and-a-half-year-old membrane, resulting in low membrane permeability due to the irreversible fouling on the surface of the membrane during its lifetime. Consequently, it is expected that the permeate flux could be set to considerably higher values after chemical membrane cleaning, probably requiring no increase of the gas sparging intensity.

Figure 6 shows that the fuzzy-logic controller proposed in this study performed adequately: the fouling rate remained close to its set point when there were no constraints on the gas sparging intensity. Indeed, in spite of the considerable variation in the permeate flux the controlled variable remained at quite suitable values, highlighting that the proposed fuzzy-logic controller performed well under conditions similar to 
1 those expected in full-scale SAnMBR systems.

Figure 7 shows the average daily membrane performance logged whilst using the control system for one month. The average MLTS concentration entering the membrane

7 tank during the operating period ranged from around 16 to $18 \mathrm{~g} \mathrm{~L}^{-1}$. This variation in

8 MLTS was caused by the dynamics of the influent flow and load entering the

9 demonstration plant. The results shown in Figure 7 can be divided in two different periods: whilst the controller was not calibrated (until day 9) and when fully adjusted (after day 9). Before the advanced control system was implemented, the membranes were operated by time-based filtration sequences (resulting in a $\mathbf{J}_{20}$ of $8 \mathrm{LMH}$ ) with constant gasification intensity ( $\mathrm{SGD}_{\mathrm{m}}$ of $0.35 \mathrm{Nm}^{3} \mathrm{~h}^{-1} \mathrm{~m}^{-2}$ ). The time-based filtration sequences entailed a specific schedule consisting of a combination of different individual stages (back-flushing, degasification and ventilation) taken from a basic F-R cycle. The time-based operating mode was as follows: a 300-second basic F-R cycle (250 s filtration and 50 s relaxation), 30 seconds of back-flush every 10 F-R cycles, 40 seconds of ventilation every 10 F-R cycles, and 30 seconds of degasification every 50 F-R cycles.

The savings made in specific gas demand $\left(\mathrm{SGD}_{\mathrm{m}}, \mathrm{SGD}\right)$ after implementing the proposed control system (in comparison with the previous time-based membrane operating mode) is shown in Figure 7 as a clear area (i.e. the difference between the applied specific gas demand and the maximum y-axis value: $0.35 \mathrm{Nm}^{3} \mathrm{~h}^{-1} \mathrm{~m}^{-2}$ ). Comparing the results shown in Figure 7 with those of the previous operating period in which membranes were operated at a fixed BRF of $0.35 \mathrm{Nm}^{3} \mathrm{~h}^{-1} \mathrm{~m}^{-2}$, reveals energy 
1 savings during membrane scouring of up to $60 \%$ (calculated theoretically by

2 considering the energy needed for adiabatic compression according to the classic

3 mechanical energy balance). Indeed, the energy demand for membrane scouring was

4 reduced from approx. 0.36 to $0.15 \mathrm{kWh} \mathrm{m}^{-3}$.

5

6

As Figure 7 shows, even whilst operating sub-optimally (until day 9), the controller

7 allowed a slight reduction in the energy required for membrane scouring. On the other

8 hand, after tuning the control system, an $\mathrm{SGD}_{\mathrm{m}}$ of around $0.23 \mathrm{Nm}^{3} \mathrm{~h}^{-1} \mathrm{~m}^{-2}$ was enough

9 to operate the two-and-a-half-year-old membranes sub-critically (see Figure 7a). As a

Taking into account how long membranes last if not chemically cleaned or recovered (as reflected by the low permeability values), the results shown in this study predict that operating a full-scale SAnMBR using the proposed advanced control system would be quite sustainable. For instance, Judd and Judd [1] reported average $\mathrm{SGD}_{\mathrm{m}}$ and SGDP values of $0.57 \mathrm{Nm}^{3} \mathrm{~h}^{-1} \mathrm{~m}^{-2}$ and 27.5 , respectively, in full-scale WWTPs treating urban wastewater with submerged aerobic MBRs featuring flat-sheet membranes. The same authors reported average $\mathrm{SGD}_{\mathrm{m}}$ and $\mathrm{SGD}_{\mathrm{P}}$ values of $0.3 \mathrm{Nm}^{3} \mathrm{~h}^{-1} \mathrm{~m}^{-2}$ and 16 , respectively, when the membranes were hollow-fibre. These full-scale aerobic operating results are similar to the results obtained in our study because the MLTS levels applied in our study (approx. $20 \mathrm{~g} \mathrm{~L}^{-1}$ ) were higher than those in aerobic MBRs (ranging from around 12 to $\left.18 \mathrm{~g} \mathrm{~L}^{-1}\right)$. In addition, the lifespan of the membranes in our study must be taken into account. 
As regards the physical cleaning stages, the average ventilation and back-flushing

3 frequencies were about 21 and 5, respectively. The total downtime caused by physical

4 cleaning therefore accounted for less than $2 \%$ of operating time.

5

6

Table 3 summarises the average SAnMBR performance when operating on a time-

7 based mode and the performance of the proposed filtration control system, showing that

8 far greater energy savings could be achieved by the proposed control system than the

9 time-based fixed operating mode.

10

The proposed advanced control system enables adequate filtration performance;

makes use of the on-line equipment available in the plant; and is user-friendly and

13 adaptable to new operating requirements.

14

4.4. Overall performance of the SAnMBR system

16

As mentioned earlier, the filtration system controller was tested using a membrane tank that continuously recycled the permeate back into the system. As Figure 4a shows, the permeate flow ranged from about 135 to $400 \mathrm{~L} \mathrm{~h}^{-1}\left(225 \mathrm{~L} \mathrm{~h}^{-1}\right.$ on average). As regards designing a full-scale plant, the findings set forth in this paper would be useful for determining the reaction volume giving the HRT needed to ensure that the biological process performs adequately.

Previous research on this SAnMBR system has shown that acceptable COD removal efficiencies (of around 90\%) can be accomplished in a wide range of operating conditions: SRT of 20 - 70 days, ambient temperature conditions $\left(14-33{ }^{\circ} \mathrm{C}\right)$, OLR of 
$10.5-2 \mathrm{kgCOD} \mathrm{m}{ }^{-3} \mathrm{~d}^{-1}$, and HRT of $5-24$ hours. These results shows that this SAnMBR

2 system would be able to treat the organic load occurring at the peak flow simulated in

3 this study by applying Copp's influent data.

4

5

Biogas was produced at a significant rate on average (around $100 \mathrm{~L} \mathrm{~d}^{-1}$ ) throughout

6 the experimental period. A fraction of the biogas stored in the anaerobic reactor head

7 space was recycled through the membrane tanks to scour them which enabled the ORP

8 and $\mathrm{pH}$ in the mixed liquor to remain relatively stable at around $450-500 \mathrm{mV}$ and 6.5-

9 7.1, respectively. An equilibrium between liquid and gas phases in SAnMBR systems was observed [36], i.e. the $\mathrm{CO}_{2}$ content of the effluent was similar to the $\mathrm{CO}_{2}$ saturation point. Hence, most of the $\mathrm{CO}_{2}$ produced remained in the mixed liquor and acted as a $\mathrm{pH}$ buffer. This was confirmed by the high Alk content of the mixed liquor (around 600 $\mathrm{mgCaCO}_{3} \mathrm{~L}^{-1}$ during the operating period), in comparison with the influent Alk (around $\left.332 \mathrm{mgCaCO}_{3} \mathrm{~L}^{-1}\right)$. This behaviour highlights the importance of scouring the membranes with a fraction of the biogas produced by SAnMBR systems because according to recent literature, $\mathrm{pH}$ is a key factor in membrane fouling $[37,38]$.

As regards the impact of SRT on membrane fouling, a considerably higher propensity to irreversible fouling was observed when SRT was 20 days rather than 70 days. This was attributed mainly to the fact that EPS and SMP concentrations were higher when SRT was lower (data not shown). Furthermore, it is well known that at any given reactor volume, the higher the SRT, the higher the MLTS in the system. MLTS directly reduces $\mathrm{K}$ [31], resulting in higher operating costs. Therefore, a compromise must be struck between SRT and MLTS levels in order to minimise both irreversible membrane fouling and operating costs. On the basis of the results obtained, we propose that SAnMBR systems be operated with MLTS levels of approximately 15 to $20 \mathrm{~g} \mathrm{~L}^{-1}$ in 
1 the membrane tank and a minimum SRT of 40 days.

2

3 5. Conclusions

4

5

6 been developed, fine-tuned and validated. It consists of lower-layer controllers (classical

7 on-off and PID controllers) and an upper-layer (knowledge-based) control. The results

8 of this study suggest that the proposed control system is promising: low fouling rates

9 (almost $0 \mathrm{mbar}^{\mathrm{min}}{ }^{-1}$ ) were achieved by applying sustainable gas sparging intensities (approx. $0.23 \mathrm{Nm}^{3} \mathrm{~h}^{-1} \mathrm{~m}^{-2}$ ). Moreover, ventilation and back-flushing downtimes were

11 reduced considerably (to around $2 \%$ of total operating time) in comparison with full-

12 scale aerobic MBRs.

13

Acknowledgements

15

This research has been supported by the Spanish Research Foundation (CICYT Projects CTM2008-06809-C02-01 and CTM2008-06809-C02-02, and MICINN FPI grant BES-2009-023712) and Generalitat Valenciana (Projects GVA-ACOMP2010/130 and GVA-ACOMP2011/182), which are gratefully acknowledged.

\section{References}

[1] S. Judd, C. Judd, The MBR Book: Principles and Applications of Membrane Bioreactors for Water and Wastewater Treatment, second ed., Elsevier, ISBN: 978-0-08-096682-3, 2011.

[2] I.S. Chang, P. L. Clech, B. Jefferson, S. Judd, Membrane fouling in membrane bioreactors for wastewater treatment, J. Environ. Eng. 128(2002), $1018-1029$.

27 [3] C. Huyskens, E. Brauns, E. Van Hoof, L. Diels, H. De Wever, Validation of a supervisory control 
system for energy savings in membrane bioreactors, Water Res. 45 (2011), 1443 - 1453.

[4] S. Judd, The status of membrane bioreactor technology, Trends in Biotechnology 26 (2008), 109 116.

[5] A. Drews, Membrane fouling in membrane bioreactors - Characterisation, contradictions, cause and cures, J. Membr. Sci. 363 (2010), 1 - 28.

[6] S.I. Patsios, A.J. Karabelas, An investigation of the long-term filtration performance of a membrane bioreactor (MBR): The role of specific organic fractions, J. Membr. Sci. 253 (2011), $102-115$.

[7] A. Robles, M.V. Ruano, F. García-Usach, J. Ferrer, Sub-critical filtration conditions of commercial hollow-fibre membranes in a submerged anaerobic MBR (HF-SAnMBR) system: The effect of gas sparging intensity, Bioresour. Technol. 114 (2012), 247 - 254.

[8] P. Bachin, P. Aimar, V. Sanchez, Model for colloidal fouling of membranes, AIChE J. 41 (1995), 368 $-377$.

[9] R.W. Field, D. Wu, J.A. Howell, B.B. Gupta, Critical flux concept for microfiltration fouling, J. Membr. Sci. 100 (1995), $259-272$.

[10] B. Verrecht, T. Maere, I. Nopens, C. Brepols, S. Judd, The cost of a large-scale hollow fibre MBR, Water Res. 44 (2010), $5274-5283$.

[11] A. Drews, H. Arellano-Garcia, J. Schöneberger, J. Schaller, M. Kraume, G. Wozny, Improving the efficiency of membrane bioreactors by a novel model-based control of membrane filtration, $17^{\text {th }}$ European Symposium on Computer Aided Process Engineering - ESCAPE 17(2007), 345 - 350.

[12] A. Drews, H. Arellano-Garcia, J. Schöneberger, J. Schaller, G. Wozny, M. Kraume, Model-based recognition of fouling mechanisms in membrane bioreactors, Desalination 236 (2009), 224 - 233.

[13] J. Busch, A. Cruse, W. Marquardt, Run-to-Run Control of Membrane Filtration Processes, AIChE J. 53 (2007), $2316-2328$.

[14] G. Ferrero, I. Rodriguez-Roda, J. Comas, Automatic control systems for submerged membrane bioreactors: A state-of-the-art review, Water Res. 46 (2012), 3421 - 3433.

[15] C. Huyskens, E. Brauns, E. Van Hoof, H. De Wever, A new method for the evaluation of the reversible and irreversible fouling propensity of MBR mixed liquor, J. Membr. Sci. 323 (2008), 185 192.

[16] H. Monclús, G. Buttiglieri, G. Ferrero, I. Rodriguez-Roda, J. Comas, Knowledge-based control module for start-up of flat sheet MBRs, Bioresour. Technol. 106 (2012), 50 - 54.

[17] G. Ferrero, H. Monclús, G. Buttiglieri, S. Gabarron, J. Comas, I. Rodriguez-Roda, Development of a 
control algorithm for air-scour reduction in membrane bioreactors for wastewater treatment, J. Chem. Technol. Biotechnol. 86 (2010), $784-789$.

[18] G. Ferrero, H. Monclús, G. Buttiglieri, J. Comas, I. Rodriguez-Roda, Automatic control system for energy optimization in membrane bioreactors, Desalination 268 (2011), 276 - 280.

[19] G. Ferrero, H. Monclús, L. Sancho, J.M. Garrido, J. Comas, I. Rodriguez-Roda, A knowledge-based control system for air-scour optimisation in membrane bioreactors, Water Sci. Technol. 63 (2011), 2025 $-2031$.

[20] D. Jeison, J.B. van Lier, On-line cake-layer management by trans-membrane pressure steady state assessment in Anaerobic Membrane Bioreactors for wastewater treatment, Biochem. Eng. J. 29 (2006), $204-209$.

[21] P.J. Smith, S. Vigneswaran, H.H. Ngo, R. Ben-Aim, H. Nguyen, A new approach to backwash initiation in membrane systems, J. Membr. Sci. 278 (2006), 381 - 389.

[22] A. Vargas, I. Moreno-Andrade, G. Buitrón, Controlled backwashing in a membrane sequencing batch reactor used for toxic wastewater treatment, J. Membr. Sci. 320 (2008), 185 - 190.

[23] H-D. Park, Y.H. Lee, H-B. Kim, J. Moon, C-H. Ahn, K-T. Kim, M-S. Kang, Reduction of membrane fouling by simultaneous upward and downward air sparging in a pilot-scale submerged membrane bioreactor treating municipal wastewater, Desalination 251 (2010), $75-82$.

[24] L.A. Zadeh, Fuzzy sets, Information and Control 8 (1965), 338 - 353.

[25] H.B. Verbruggen, P.M. Bruijn, Fuzzy control and conventional control: What is (and can be) the real contribution of Fuzzy Systems?, Fuzzy Set. Syst. 90 (1997), 151 - 160.

[26] M.V. Ruano, J. Ribes, G. Sin, A. Seco, J. Ferrer, A systematic approach for fine-tuning of fuzzy controllers applied to WWTPs, Environ. Modell. Softw. 25 (2010), 670 - 676.

[27] M.V. Ruano, J. Ribes, A. Seco, J. Ferrer, An advanced control strategy for biological nutrient removal in continuous systems based on pH and ORP sensors, Chem. Eng. J. 183 (2012), 212 - 221. [28] J.B. Giménez, A. Robles, L. Carretero, F. Durán, M.V. Ruano, M.N. Gatti, J. Ribes, J. Ferrer, A. Seco, Experimental study of the anaerobic urban wastewater treatment in a submerged hollow-fibre membrane bioreactor at pilot scale, Bioresour. Technol. 102 (2011), 8799 - 8806.

[29] American Public Health Association/American Water Works Association/Water Environmental Federation, Standard methods for the Examination of Water and Wastewater, $21^{\text {st }}$ edition, Washington DC, USA, 2005.

[30] Water Research Commission, University of Cape Town, Simple titration procedures to determine 
H2CO3* alkalinity and short-chain fatty acids in aqueous solutions containing known concentrations of ammonium, phosphate and sulphide weak acid/bases, Report No. TT 57/92, Pretoria, Republic of South Africa, 1992.

4 [31] A. Robles, F. Durán, M.V. Ruano, J. Ribes, J. Ferrer, Influence of total solids concentration on membrane permeability in a submerged hollow-fibre anaerobic membrane bioreactor, Water Sci. Technol. 66 (2012), $377-384$.

7 [32] H. Monclús, G. Ferrero, G. Buttiglieri, J. Comas, I. Rodriguez-Roda, On-line monitoring of 8 membrane fouling in submerged MBRs, Desalination 277 (2011), $414-419$.

9 [33] P.M. Larsen, Industrial application of fuzzy logic control, Int. J. Man. Mach. Stud. 12 (1980), 3 - 10.

10 [34] J.M. Mendel, Fuzzy logic systems for engineering: a tutorial, Proc. IEEE 83 (1995), 345 - 375.

[35] J.B. Copp, Development of standardised influent files for the evaluation of activated sludge control strategies, IAWQ Scientific and Technical Report Task Group: Respirometry in Control of the Activated Sludge Process - internal report, 1999.

[36] J.B. Giménez, N. Martí, J. Ferrer, A. Seco, Methane recovery efficiency in a submerged anaerobic membrane bioreactor (SAnMBR) treating sulphate-rich urban wastewater: Evaluation of methane losses with the effluent, Bioresour. Technol. 118 (2012), 67 - 72. 1287.

[38] A. Sweity, W. Ying, S. Belfer, G. Oron, M. Herzberg, pH effects on the adherence and fouling propensity of extracellular polymeric substances in a membrane bioreactor, J. Membr. Sci. 378 (2011), $186-193$. 


\section{$1 \quad$ Figure and table captions}

2

3 Figure 1. Simplified lay-out of the SAnMBR demonstration plant where the control system was 4 designed.

5 Figure 2. Flow chart of the proposed filtration control system.

6 Figure 3. Performance of the sludge recycling controller. Evolution of sludge recycled through the 7 membrane tank $(S R F)$, set point of the sludge recycled through the membrane tank $\left(S R F_{S P}\right)$, permeate 8 flow $(F I T-P 11)$, permeate flow set point $\left(F I T-P 11_{S P}\right)$, and rotating speed of the sludge recycling pump $9 \quad(F C-P 12)$.

Figure 4. Ventilation initiation time determined by knowledge-based rule. Evolution of: (a) permeate flow set point $\left(F I T-P 11_{S P}\right)$ and membrane operating stage (V: ventilation; B: back-flushing; and F: filtration); and (b) $20^{\circ} \mathrm{C}$-normalised transmembrane flux $\left(\mathrm{J}_{20}\right), 20^{\circ} \mathrm{C}$-normalised transmembrane flux set point $\left(J_{20, S P}\right), 20^{\circ} \mathrm{C}$-normalised minimum transmembrane flux set point $\left(J_{20, S P}\right)$, and rotating speed of the permeate pump $(F C-P 11)$.

Figure 5. Back-flushing initiation time triggered by knowledge-based rules. Evolution of: (a) transmembrane pressure $(T M P)$ and membrane operating stage (V: ventilation; B: back-flushing; and F: filtration); and (b) membrane permeability $\left(K_{20}\right)$, maximum filtration membrane permeability recorded between consecutive back-flushing $\left(K_{20, M A X, F}\right)$, and maximum calibrated back-flushing membrane permeability $\left(K_{20, M A X, B F}\right)$.

Figure 6. Fuzzy-logic controller performance. Evolution of: (a) permeate flow (FIT-P11), permeate flow set point $\left(F I T-P 11_{S P}\right)$, biogas recycling flow set point $\left(B R F_{S P}\right)$ and biogas recycling flow $(B R F)$; and $(\mathbf{b})$ fouling rate $\left(F R_{C}\right)$, fouling rate set point $\left(F R_{C_{-} S P}\right)$, biogas recycling flow set point $\left(B R F_{S P}\right)$ and biogas recycling flow $(B R F)$.

Figure 7. Overall advanced control system results. Evolution of: (a) $20^{\circ} \mathrm{C}$-normalised transmembrane flux $\left(J_{20}\right)$, specific gas demand per membrane area $\left(\mathrm{SGD}_{\mathrm{m}}\right)$, and transmembrane pressure (TMP); and (b) $20^{\circ} \mathrm{C}$-normalised transmembrane flux $\left(J_{20}\right)$, specific gas demand per permeate volume $\left(\mathrm{SGD}_{\mathrm{p}}\right)$, and membrane permeability $\left(K_{20}\right)$.

28 Table 1. Average influent wastewater properties.

Table 2. Inference rules of control system.

Table 3. Overall SAnMBR operating results with control system on and off. 


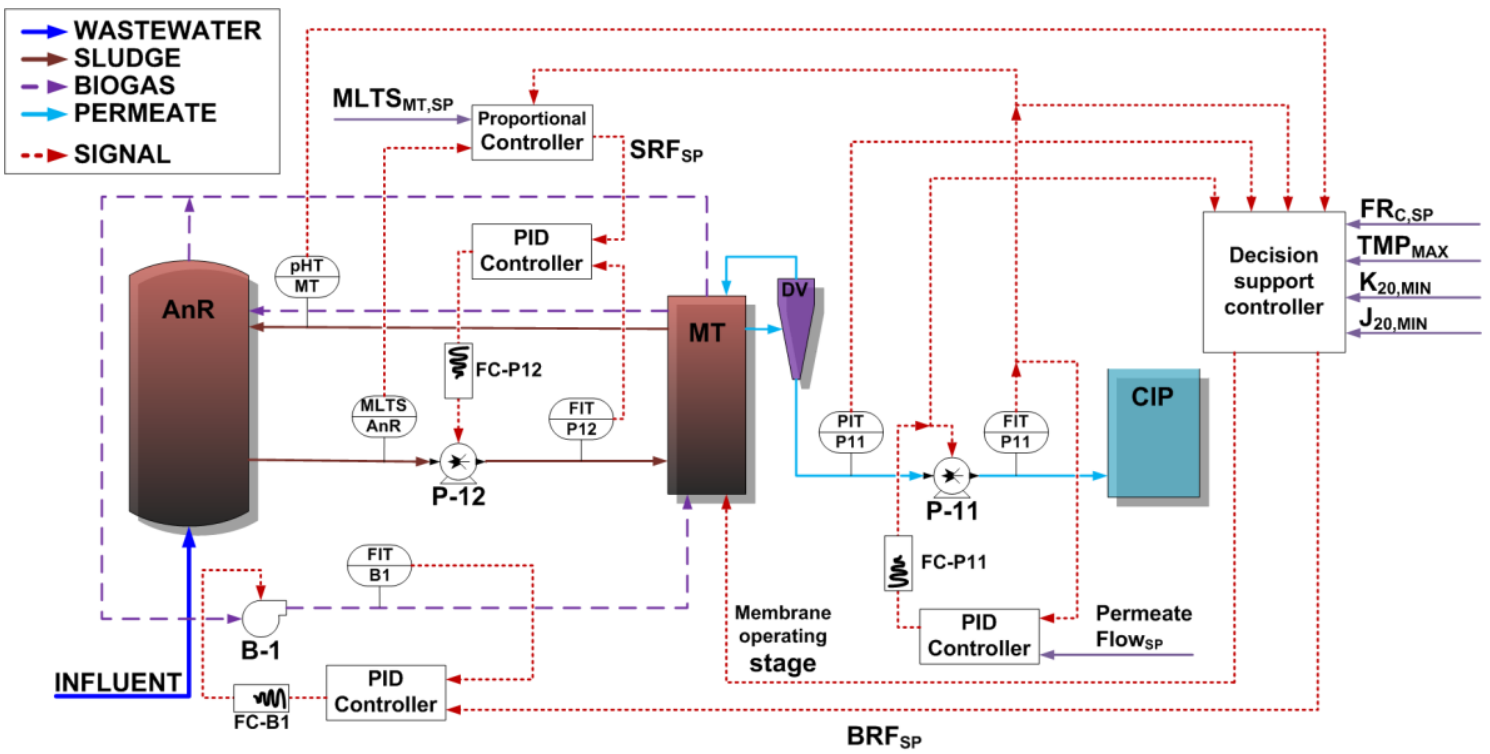

2 Figure 1. Simplified lay-out of the SAnMBR demonstration plant where the control system was

3 designed.

4

5

6

7

8

9

10

11

12

13

14

15

16

17

18

19

20

21

22 


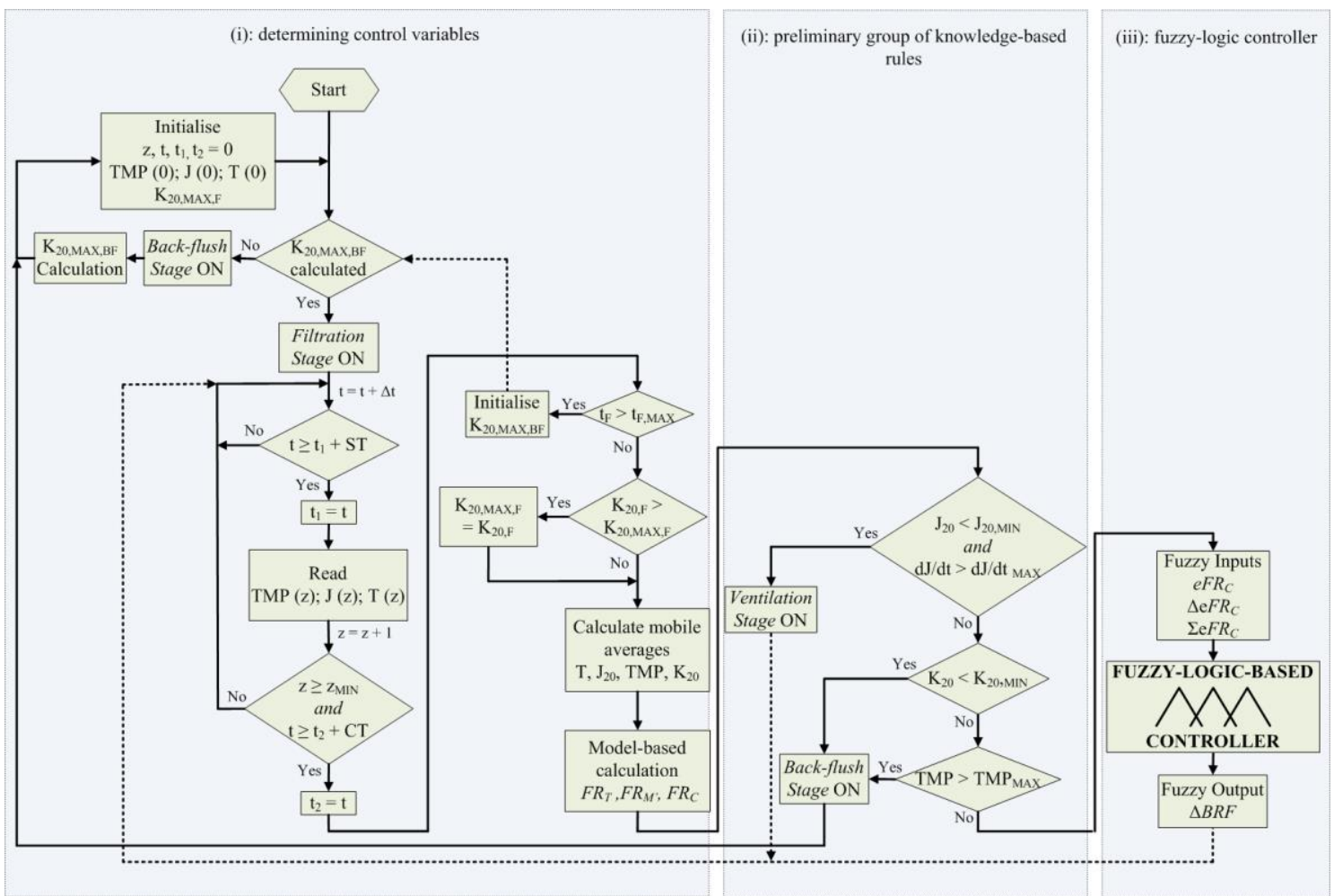

2 Figure 2. Flow chart of the proposed filtration control system.

3

4

5

6

7

8

9

10

11

12

13

14

15

16 


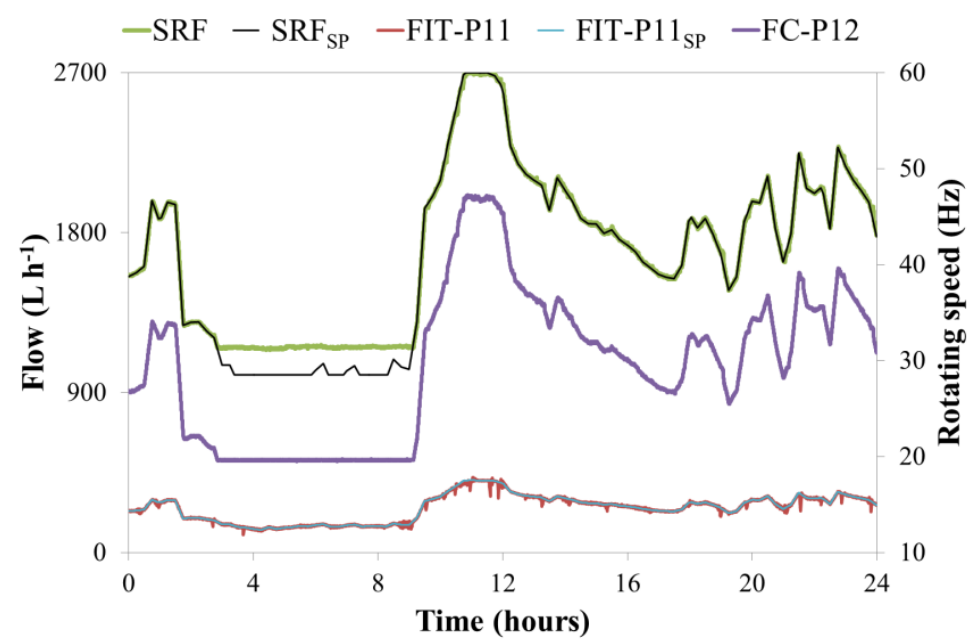

2 Figure 3. Performance of the sludge recycling controller. Evolution of sludge recycled through the

3 membrane tank $(S R F)$, set point of the sludge recycled through the membrane tank $\left(S R F_{S P}\right)$, permeate

4 flow $(F I T-P 11)$, permeate flow set point $\left(F I T-P 11_{S P}\right)$, and rotating speed of the sludge recycling pump

$5 \quad(F C-P 12)$

6

7

8

9

10

11

12

13

14

15

16

17

18

19

20

21 


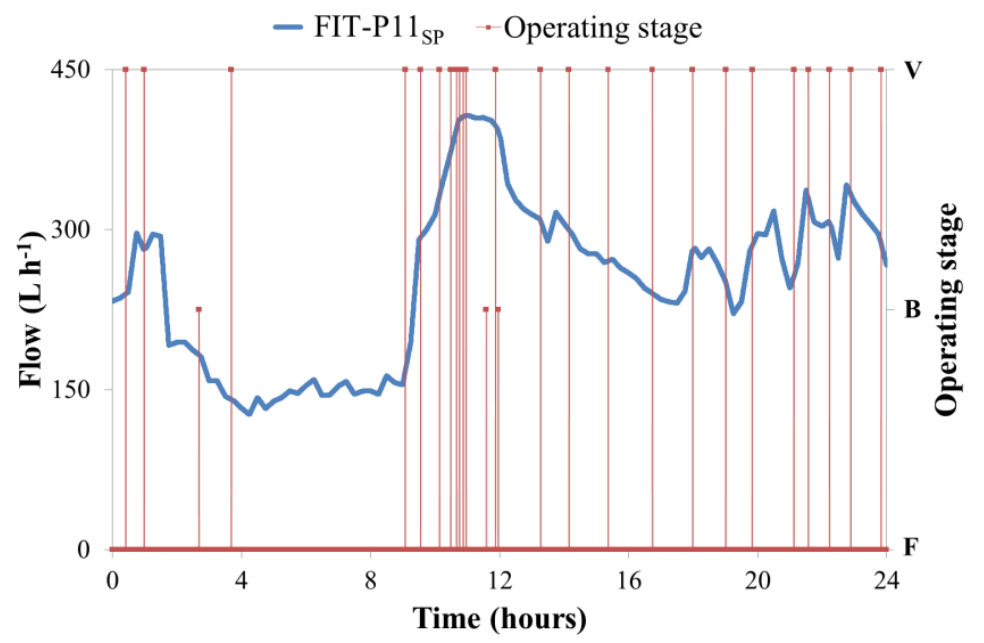

2

(a)

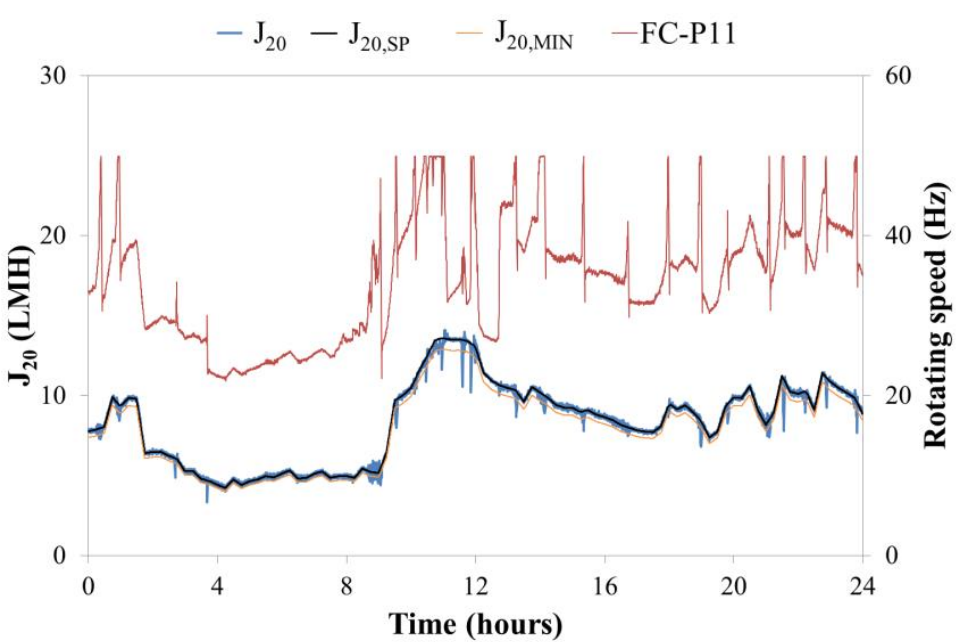

3

(b)

5 Figure 4. Ventilation initiation time determined by knowledge-based rule. Evolution of: (a) permeate

6 flow set point $\left(F I T-P 11_{S P}\right)$ and membrane operating stage (V: ventilation; B: back-flushing; and F:

7 filtration); and (b) $20^{\circ} \mathrm{C}$-normalised transmembrane flux $\left(J_{20}\right), 20{ }^{\circ} \mathrm{C}$-normalised transmembrane flux set

8 point $\left(J_{20, S P}\right), 20^{\circ} \mathrm{C}$-normalised minimum transmembrane flux set point $\left(J_{20, S P}\right)$, and rotating speed of the

9 permeate pump (FC-P11).

10

11

12

13 


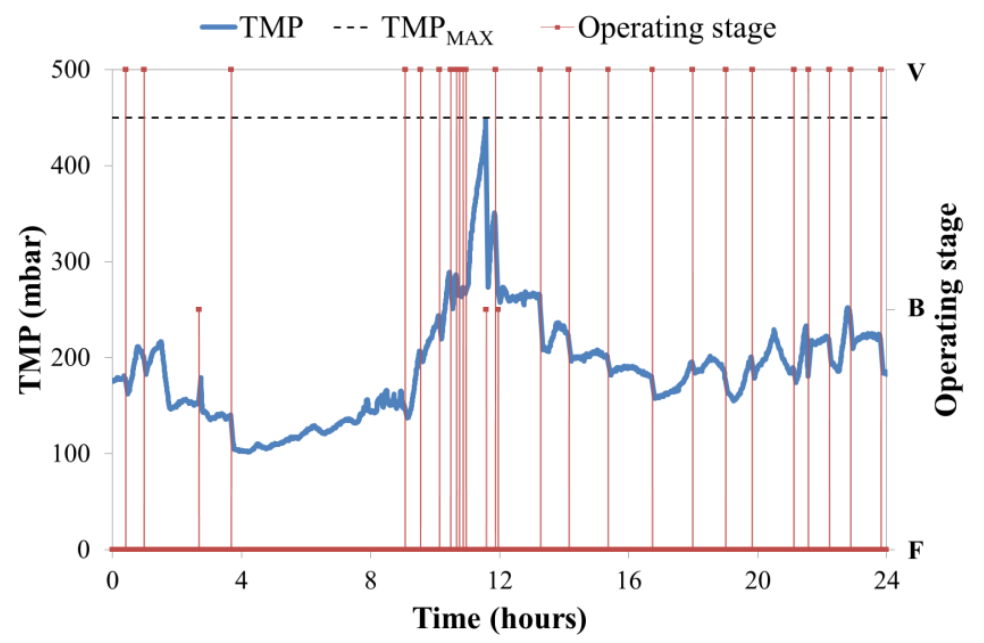

2

(a)

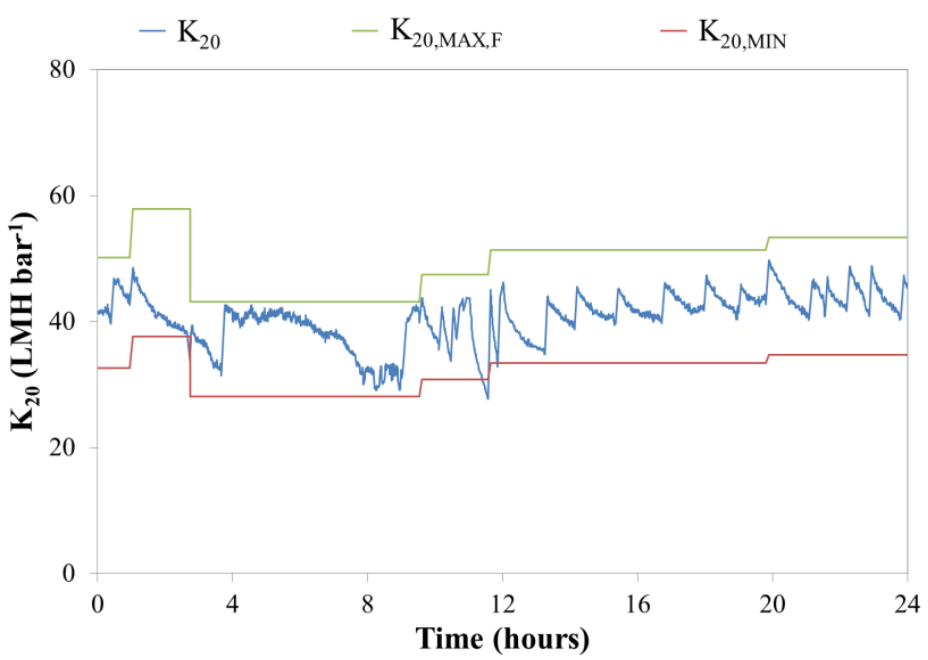

(b)

5 Figure 5. Back-flushing initiation time triggered by knowledge-based rules. Evolution of: (a)

6 transmembrane pressure (TMP) and membrane operating stage (V: ventilation; B: back-flushing; and F:

7 filtration); and (b) membrane permeability $\left(K_{20}\right)$, maximum filtration membrane permeability recorded

8 between consecutive back-flushing $\left(K_{20, M A X, F}\right)$, and maximum calibrated back-flushing membrane

9 permeability $\left(K_{20, M A X, B F}\right)$ 


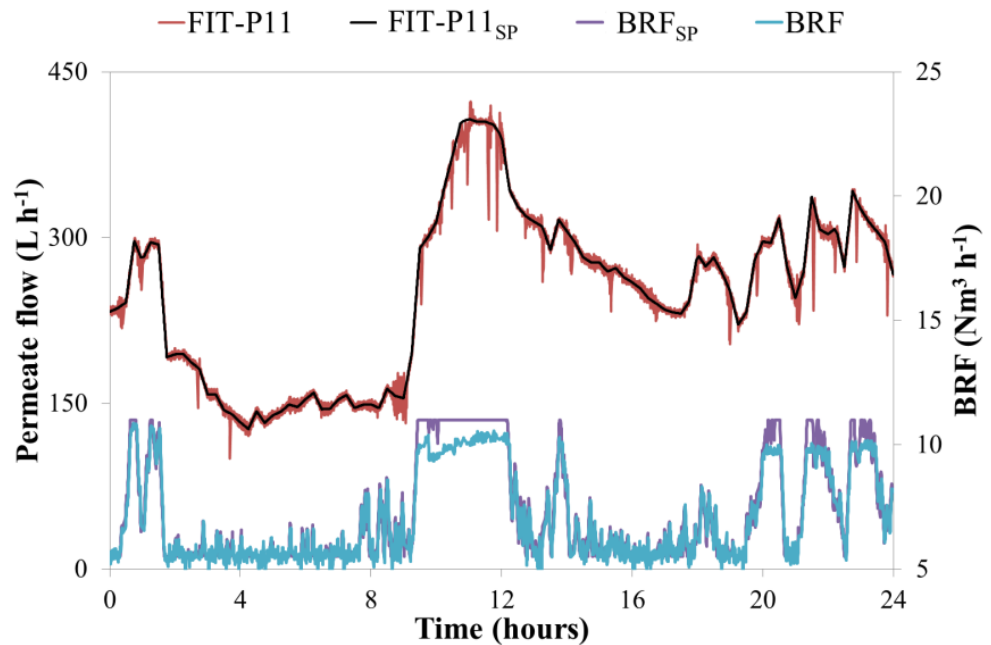

(a)

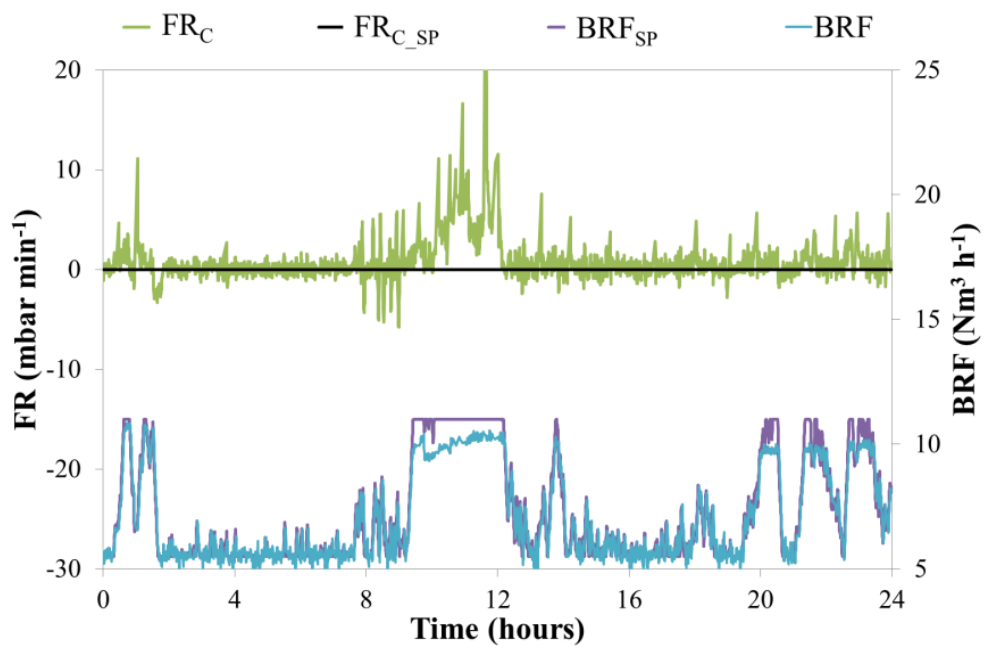

(b)

Figure 6. Fuzzy-logic controller performance. Evolution of: (a) permeate flow (FIT-P11), permeate flow set point $\left(F I T-P 11_{S P}\right)$, biogas recycling flow set point $\left(B R F_{S P}\right)$ and biogas recycling flow $(B R F)$; and $(\mathbf{b})$ fouling rate $\left(F R_{C}\right)$, fouling rate set point $\left(F R_{C_{-} S P}\right)$, biogas recycling flow set point $\left(B R F_{S P}\right)$ and biogas recycling flow $(B R F)$. 


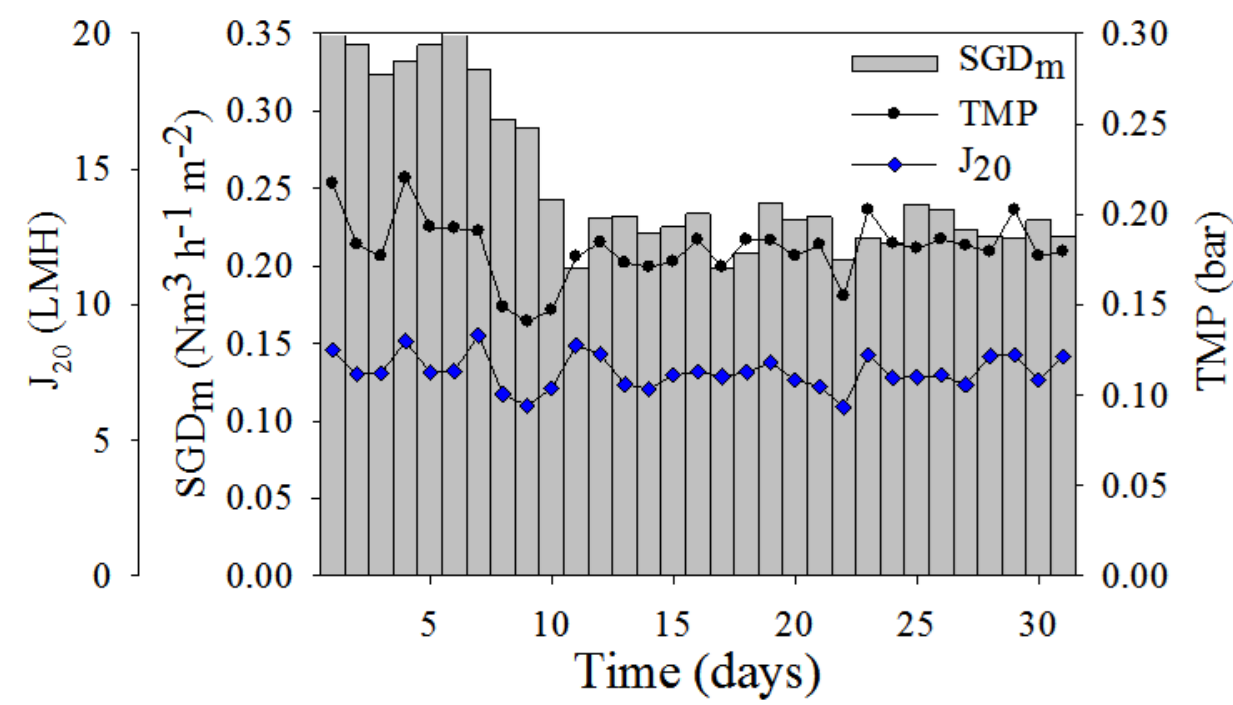

(a)

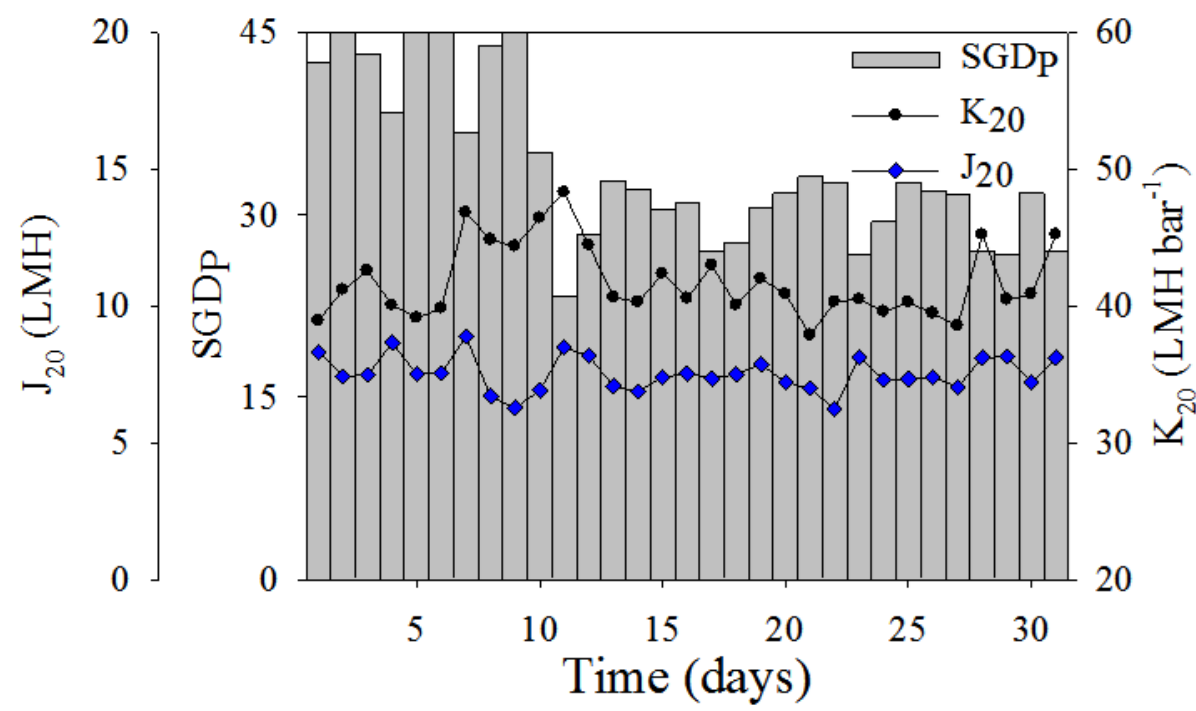

(b)
5

6

7

8

9

10

11

12

13

14 
1 Table 1. Average influent wastewater properties.

\begin{tabular}{|c|c|c|c|c|c|c|c|c|c|c|}
\hline Parameter & Unit & Mean & SD & CI $(95 \%)$ & Median & ( & $\min$ & - & $\max$ & ) \\
\hline TSS & $\mathrm{mgTSS} \mathrm{L}^{-1}$ & 323 & 176 & 16 & 286 & ( & 44 & - & 1060 & ) \\
\hline VSS & $\%$ & 80.4 & 7.9 & 0.7 & 81.4 & ( & 44.1 & - & 100.0 & ) \\
\hline $\mathrm{NH}_{4}-\mathrm{N}$ & $\mathrm{mgN} \mathrm{L}^{-1}$ & 32.2 & 8.9 & 0.9 & 32 & ( & 4.1 & - & 69.9 & ) \\
\hline $\mathrm{PO}_{4}-\mathrm{P}$ & $\mathrm{mgP} \mathrm{L}^{-1}$ & 4.0 & 1.6 & 0.2 & 3.89 & ( & 0.58 & - & 13.32 & ) \\
\hline $\mathrm{SO}_{4}-\mathrm{S}$ & $\mathrm{mgS} \mathrm{L} \mathrm{L}^{-1}$ & 105 & 13 & 2 & 103 & ( & 70 & - & 139 & ) \\
\hline Total COD & $\operatorname{mgCOD~L} L^{-1}$ & 585 & 253 & 43 & 537 & ( & 211 & - & 1472 & ) \\
\hline Soluble COD & $\operatorname{mgCOD~L}{ }^{-1}$ & 80 & 20 & 4 & 77 & ( & 32 & - & 132 & ) \\
\hline $\mathrm{pH}$ & un. $\mathrm{pH}$ & 7.7 & 0.2 & 0.02 & 7.7 & ( & 6.8 & - & 8.2 & ) \\
\hline Alk & $\mathrm{mgCaCO}_{3} \mathrm{~L}^{-1}$ & 332 & 58 & 5 & 331 & ( & 139 & - & 707 & ) \\
\hline VFA & $\mathrm{mgCOD} \mathrm{L}^{-1}$ & 7.9 & 10.5 & 0.9 & 6.3 & ( & 0 & - & 198 & ) \\
\hline
\end{tabular}

3

4

5

6

7

8

9

10

11

12

13

14

15

16

17

18

19

20

21

22

23 
Table 2. Inference rules of control system.

Inference Rules

1. If $e F R_{C}$ is $P$ and $\Sigma e F R_{C}$ is $P$ then $\triangle B R F_{S P}$ is $L P$

2. If $e F R_{C}$ is $N$ and $\sum e F R_{C}$ is $N$ then $\triangle B R F_{S P}$ is $L N$

3. If $e F R_{C}$ is $Z$ and $\sum e F R_{C}$ is $Z$ then $\triangle B R F_{S P}$ is $L N$

4. If $e F R_{C}$ is $P$ and $\triangle e F R_{C}$ is $P$ then $\triangle B R F_{S P}$ is $H P$

5. If $e F R_{C}$ is $N$ and $\triangle e F R_{C}$ is $P$ then $\triangle B R F_{S P}$ is $H N$

2

3

4

5

6

7

8

9

10

11

12

13

14

15

16

17

18

19

20

21

22

23 
1 Table 3. Overall SAnMBR operating results with control system on and off.

\begin{tabular}{lcc}
\hline Operating results & \multicolumn{1}{c}{$\begin{array}{c}\text { Time-based } \\
\text { operating mode }\end{array}$} & $\begin{array}{c}\text { Control system } \\
\text { action }\end{array}$ \\
\hline $\begin{array}{l}\text { Average } \mathrm{SGD}_{\mathrm{m}} \\
\left(\mathrm{Nm}^{3} \mathrm{~h}^{-1} \mathrm{~m}^{-2}\right)\end{array}$ & 0.35 & 0.25 \\
\hline Average SGD $\mathrm{P}$ & 45 & 30 \\
\hline $\begin{array}{l}\text { Average SRF } \\
\left(\mathrm{m}^{3} \mathrm{~h}^{-1}\right)\end{array}$ & 2.7 & 1.7 \\
\hline $\begin{array}{l}\text { Energy for membrane scouring } \\
\left(\mathrm{kWh} \mathrm{m}^{3}\right)\end{array}$ & 0.36 & 0.15 \\
\hline $\begin{array}{l}\text { Energy for pumping sludge } \\
\left(\mathrm{kWh} \mathrm{m}^{3}\right)\end{array}$ & 0.06 & 0.03 \\
\hline $\begin{array}{l}\text { Ventilation frequency } \\
(\text { initiations/day) }\end{array}$ & 27 & 21 \\
\hline $\begin{array}{l}\text { Back-flushing frequency } \\
(\text { initiations/day) }\end{array}$ & 27 & 1.4 \\
\hline $\begin{array}{l}\text { Downtime for ventilation } \\
(\%)\end{array}$ & 1.6 & 0.2 \\
\hline $\begin{array}{l}\text { Downtime for back-flushing } \\
(\%)\end{array}$ & 2.8 & 5 \\
\hline $\begin{array}{l}\text { Overall downtime for physical } \\
\text { cleaning } \\
(\%)\end{array}$ & 1.2 & 1.6 \\
\hline
\end{tabular}

3

4 